\title{
Chemical Constituents of Biological Importance in the English Channel, November, 1930, to January, 1932. Part I. Phosphate, silicate, nitrate, nitrite, ammonia. \\ By
}

L. H. N. Cooper, Ph.D., A.I.C., Assistant Chemist at the Plymouth Laboratory.

With 15 Figures in the Text.

\section{Contents.}

Station El . $\quad . \quad . \quad . \quad . \quad . \quad . \quad . \quad . \quad . \quad .681$

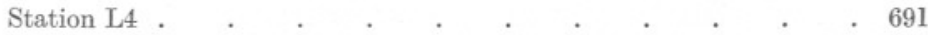

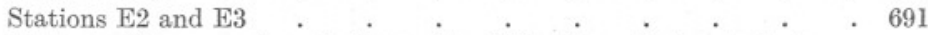

Method of Representing the Intensity of Plankton Outbursts in terms
of Change in Phosphate...
.

IV. Silicate . . . . . . . . . . . . . . . . 694

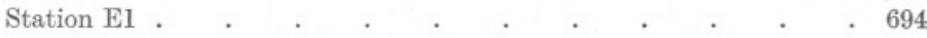

The Summer Maximum for Silicate. Mechanism of Re-solution of Silica in the Sea. $. \quad . \quad . \quad . \quad .695$

Increase in Silicate with Proximity to Shore . $\quad . \quad$. $\quad . \quad 698$

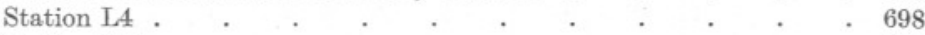

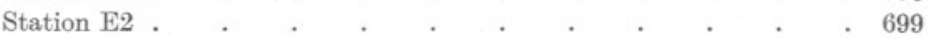

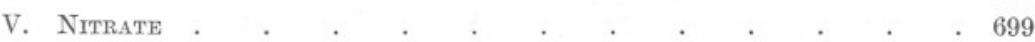

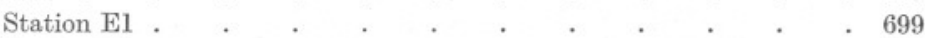

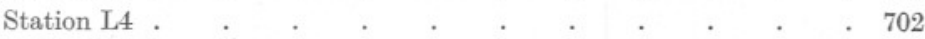

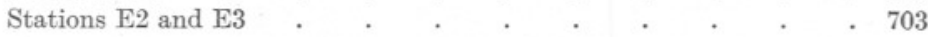

Vi. Comparative Behaviour of Nutrient Salts . $\quad . \quad$. $\quad . \quad 703$

Seasonal Variation in Daily Consumption and Regeneration of Nutrient Salts . $.5 . \quad . \quad . \quad . \quad .703$

Comparison of the Magnitude and Date of Occurence of the Winter Maxima for Phosphate, Silicate and Nitrate . . . . 705

Apparent Efficiency of Utilisation of Phosphate and Nitrate . . 706

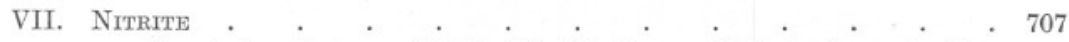

Correlation between Nitrite Distribution and Hydrodynamic Conditions . .4 .608

The Behaviour of Nitrite in the English Channel, Barents Sea and Antarctic Waters . . . . . . . . 709

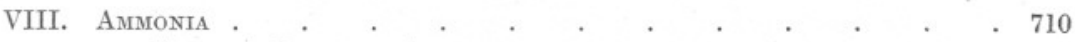

Seasonal Changes in Ammonia . . . . . . . 710 


IX. The Interconversion of Ammonia, Nitrite and Nitrate
X. The Gram Atom as a Common Rational Unit For Nutrient
XI. Malts

\section{INTRODUCTION.}

Is studying the fertility of the sea and its suitability for the production of the microscopic plant life which forms the ultimate foodstuff of other life in the sea, it is desirable to accumulate an unbroken series of data on the inorganic nutrient salts over a period of years. Both phosphate and nitrate are essential for growth and reproduction of phytoplankton and, when possible, data for the two are desirable since each may bring out factors not shown by the other. The actual quantity determined represents at any one time a balance between salt abstracted by living organisms and that regenerated by the decay of dead material, and the balance may be struck differently for the two salts at different times of year. Regeneration of phosphate is apparently a simple liberation from proteid material, whereas the nitrogen has to be returned through a multi-stage cycle, so that regeneration of nitrate is felt later than that of phosphate.

Much work remains to be done on minor constituents of sea-water other than phosphate and nitrate before we can arrive at a satisfactory picture of the changes taking place. Further, it is not enough to investigate such substances singly on isolated occasions since the essential interrelations may then be missed. For this reason simultaneous analyses have also been made for silicate, nitrite, ammonia, oxygen, hydrogen ion concentration, and excess base. Temperature and salinity data are also available.

Attention has been concentrated on the International Hydrographic Station, E1, 22 miles S. $37^{\circ} \mathrm{W}$. from Plymouth, which is far enough from land to be but slightly affected by land drainage. Apart from the tidal flow of water up and down Channel there is, so far as can at present be seen, a small residual current, but generally speaking the character of the water remains fairly constant. Any marked change due to an influx of ocean water as in the autumn of 1921 (Harvey, 1923), or of fresh water from the land as in July, 1931 (this paper), is commonly indicated by unusual temperatures or salinities. 
Station L4, 8 miles S. $37^{\circ}$ W. from Plymouth, has been worked for surface and bottom samples in order to obtain comparative information on the effect of proximity to shore and of land drainage. Ammonia and nitrite have been determined at all the $\mathrm{L}$ series of stations which stretch from Plymouth Sound to E1 in order to determine their behaviour in inshore water. The results obtained are presented graphically. Photographic copies of the numerical data are available at the Plymouth Laboratory.

The positions of the Stations are as follows :-

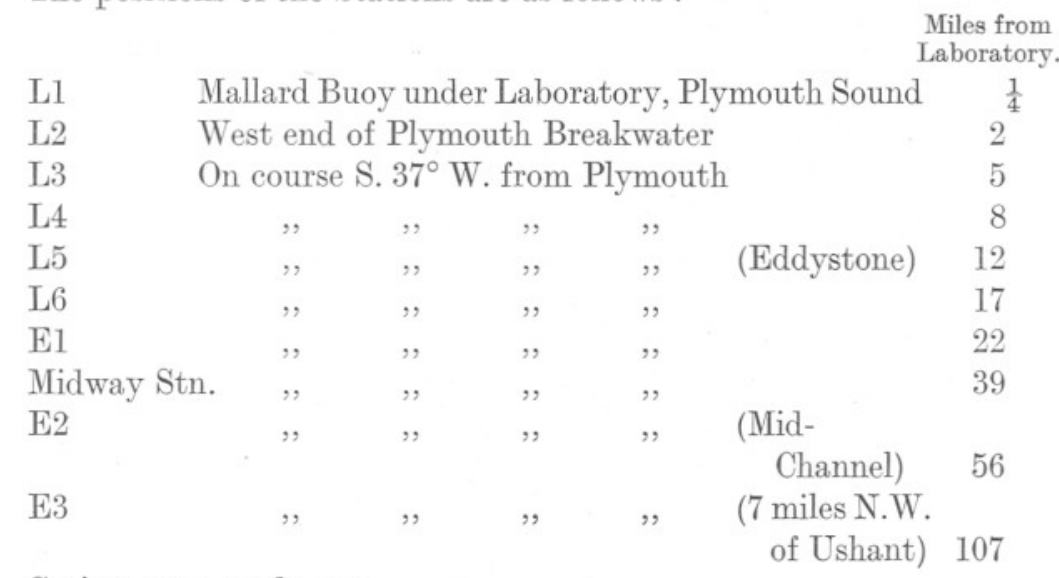

Cruises were made on :-

1930, August 12th $\left(\mathrm{P}_{2} \mathrm{O}_{5}\right.$ and $\mathrm{SiO}_{2}$ only), September 10th $\left(\mathrm{P}_{2} \mathrm{O}_{5}\right)$, October 9th (E2; $\mathrm{P}_{2} \mathrm{O}_{5}$ and $\mathrm{SiO}_{2}$ ), November 11th (complete series), December 4th.

1931, January 13th, February 4th (E3), February 19th, March 23rd, April 7th, April 22nd (E2), May 18th, July 10th, August 26th (E2), September 8th, September 25th, October 20th, November 30th (E2), December 31st.

1932, January 28th.

Complete series of analyses were not made on February 4th and December 31st, 1931, and January 28th, 1932.

\section{TEMPERATURE, SALINITY, AND WEATHER CONDITIONS.}

The distribution of salinity and temperature will be discussed by Harvey in his work on the Hydrography of the English Channel. Numerical records are available in the Rapport Atlantique, 1930 and 1931 (Rapp. et procès-verbaux du Cons. Int.). The most interesting occurrence was the low salinity of the water above the thermocline at E1 in July 
due to river water spreading over the surface following the heavy rainfall over South-Western England during June and early July, 1931. The temperature changes are shown as profiles in Fig. 1 (E1) and Fig. 7 (E2).

Sunshine much in excess of normal occurred in January, 1931. February
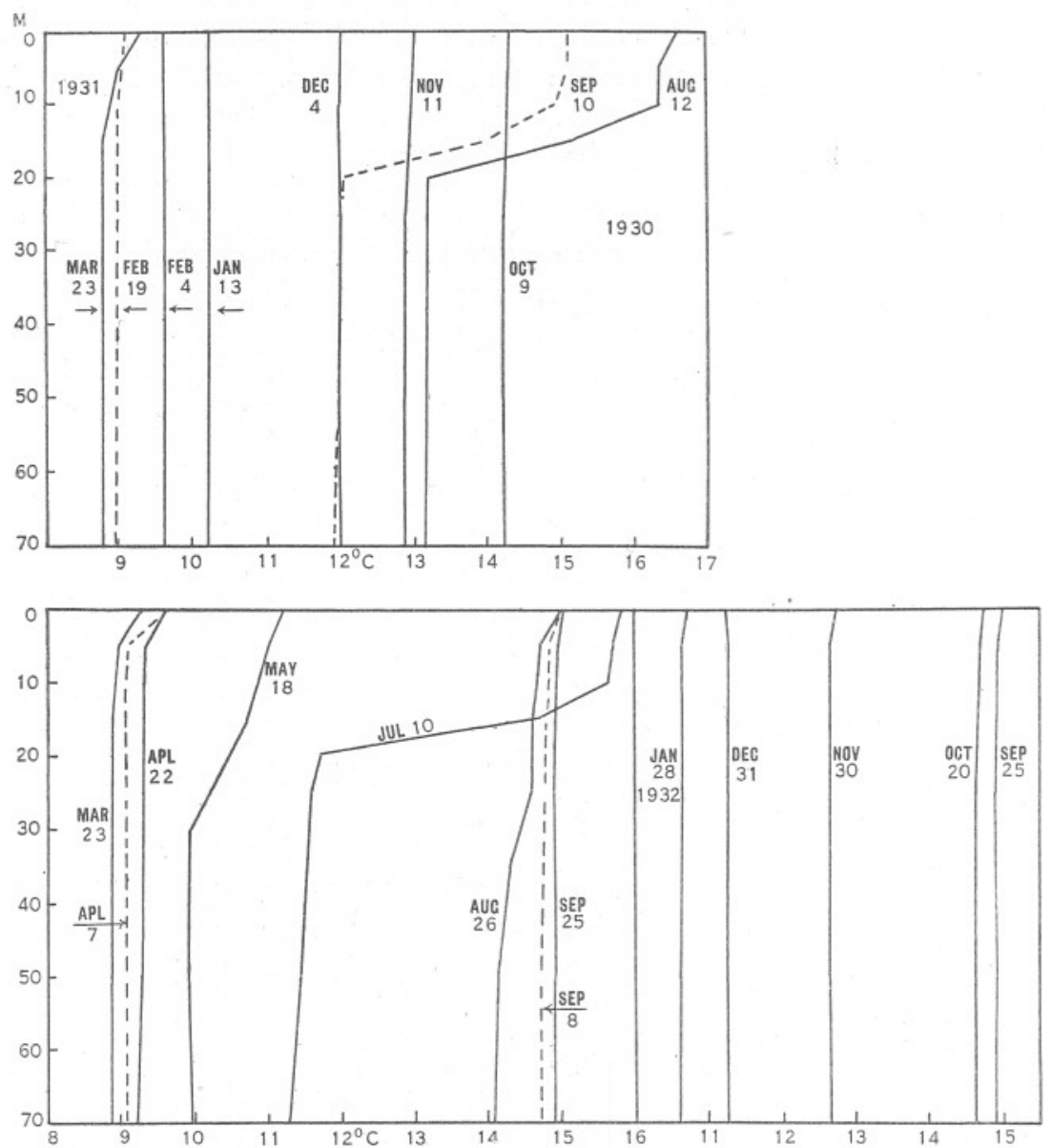

Fig. 1.-Temperature profiles at Station E1, August, 1930, to January, 1932. The first panel shows the records from August 12th, 1930, until the winter minimum on March 23rd, 1931. The second illustrates the period from March 23rd until the maximum on September 25th, 1931. The last shows the autumn isothermal cooling. The late formation and early breakdown of the thermocline in 1931 are clearly shown.

was also a sunny month (Table I). This favoured the early onset of diatom growth on the north side of the Channel. From March right on to the end of the "summer", sunshine was much below normal. This sunless weather was accompanied by overcast skies and windy and rainy weather gener- 
ally. In consequence the thermocline was late in forming, allowing the bottom stores of nutrient salts to be very completely used up, and as a result of the severe August gales it broke up exceptionally early. On August 26th it was found to have been completely obliterated at E1, there being an almost uniform gradient from surface to bottom. At E2 a thermocline was found, but at the unusual depth of 45 metres. After the 26th, the gales returned and completed the work of vertical mixing by September 8 th.

\section{TABLE I.}

Hours of Sunshine Per Day.

1931

Normal*

Plymouth (Mt. Batten)

Channel Islands广

$\begin{array}{rrrrrrrrc}\text { Jan. } & \text { Feb. } & \text { Mar. } & \text { Apr. } & \text { May. June. July. } & \text { Aug. } & \text { Sept. } \\ 1 \cdot 67 & 2 \cdot 63 & 3 \cdot 96 & 5 \cdot 53 & 6 \cdot 58 & 6 \cdot 79 & 6 \cdot 39 & 6 \cdot 04 & 4 \cdot 96 \\ 2 \cdot 77 & 2 \cdot 61 & 3 \cdot 66 & 4 \cdot 05 & 5 \cdot 28 & 5 \cdot 82 & 4 \cdot 77 & 5 \cdot 08 & 4 \cdot 22 \\ 1 \cdot 92 & 2 \cdot 54 & 3 \cdot 87 & 5 \cdot 58 & 6 \cdot 56 & 8 \cdot 86 & 7 \cdot 63 & 5 \cdot 38 & 4 \cdot 84 ?\end{array}$

\section{PHOSPHATE.}

Atkins (1923 (1) et seq.) has published data for phosphate from March, 1923, to April, 1929, with a gap from March to October, 1927. The series, resumed by the writer in August, 1930, was continued to January, 1932, when work was stopped owing to illness.

\section{Station E1.}

The seasonal variation in phosphate with depth at E1 is shown in Figs. 2 and 8. During August, 1930, there was little change in the water column, but onwards from the end of September steady regeneration led to the winter maximum being reached in December when surface and bottom were markedly richer than the middle layers. A similar distribution is apparent in the profiles for January and February and favours the view that regeneration was largely a surface and bottom phenomenon. Such a distribution in winter was found in the earlier work of Atkins (1930 (2), Table 3 and p. 850, $\S 4$ ), which thus receives yet further confirmation.

Surface depletion was very marked during late December, 1930, or early January, 1931. This was not entirely due to mixing in of the enriched surface layer since the whole column showed a similar though somewhat smaller decrease which seems to point to a small mid-winter outburst. Similar mid-winter outbursts occurred in mid-December, 1925, and late December, 1926 (Atkins, 1930, p. 829). During the latter half of January the phosphate-content of the surface increased slightly although the column as a whole showed a slight decrease during a period of the year

\footnotetext{
* Normal number of hours of bright sunshine per day for South Wales and South Western England. The normals for the Channel Islands are considerably greater.

$\dagger$ Mean of Jersey and Guernsey.
} 
when the maximum is often reached. Since the average daily sunshine for January was $2 \cdot 75$ hours - $50 \%$ above the normal for the month and the highest recorded since phosphate determinations were begun here in

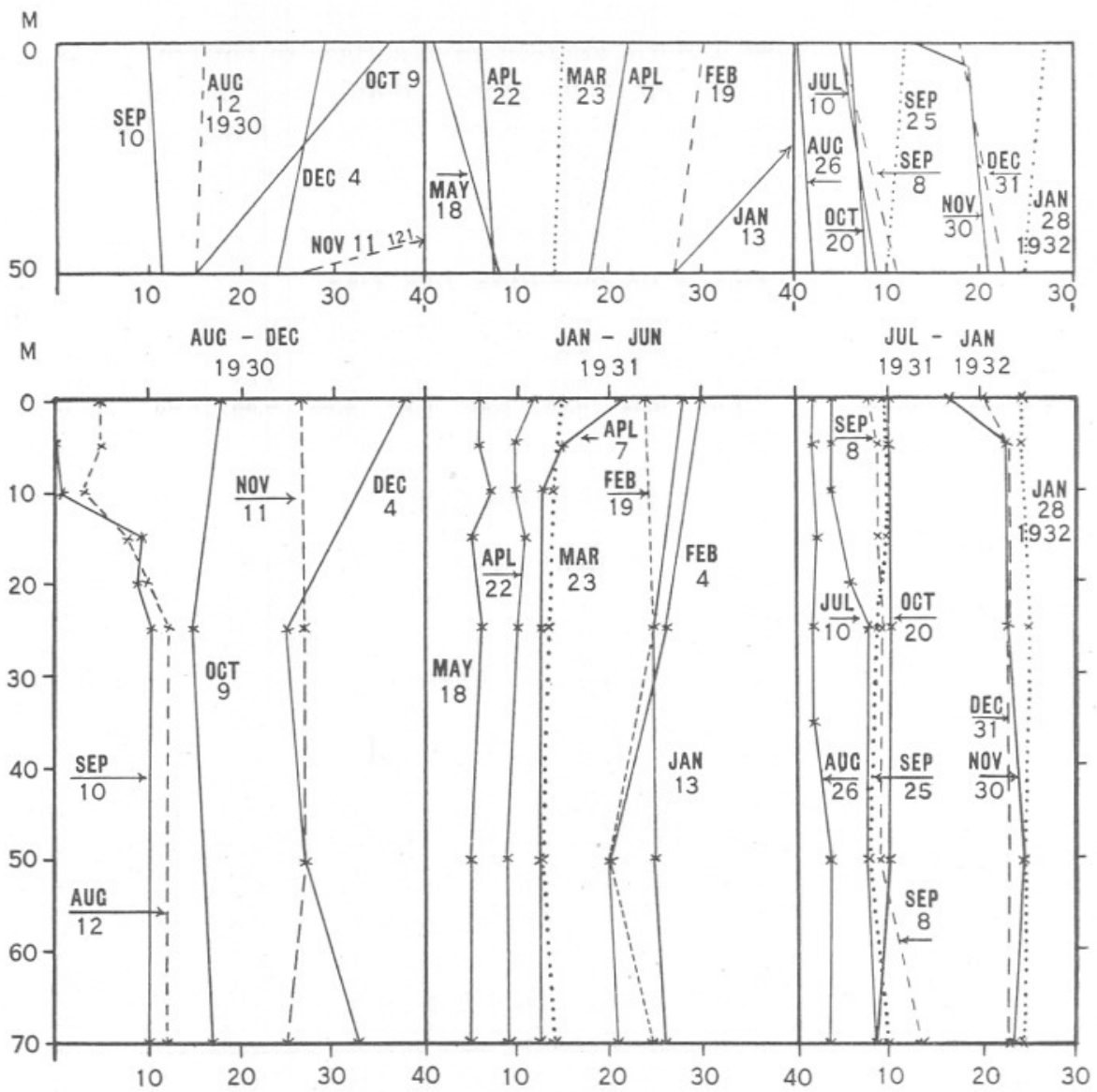

Fig. 2.-Profiles showing variation of phosphate with depth August, 1930, to January, 1932, as mg. $\mathrm{P}_{2} \mathrm{O}_{5}$ per $\mathrm{m}^{3}$. The depth scale for L4 (top) is half that for El (bottom). The spring consumption by diatoms commencing in March, 1931, and regeneration in the autumn of 1930 and late autumn of 1931 are clearly shown. The static condition existing between September 8th and October 20th, 1931, is noteworthy, as is also the very low value shown by the whole column on August 26th, 1931 (cf. August 12th, 1930, which is " normal "), (cf. Atkins, 1930, Fig. 1, p. 824).

1923 - it seems possible that regeneration was being just balanced by an incipient diatom outbreak. The excessive sunshine in January was no doubt associated with the prevalent north sector winds (cf. Atkins, 1928) and probably started an outburst which went on with increasing impetus during February. 

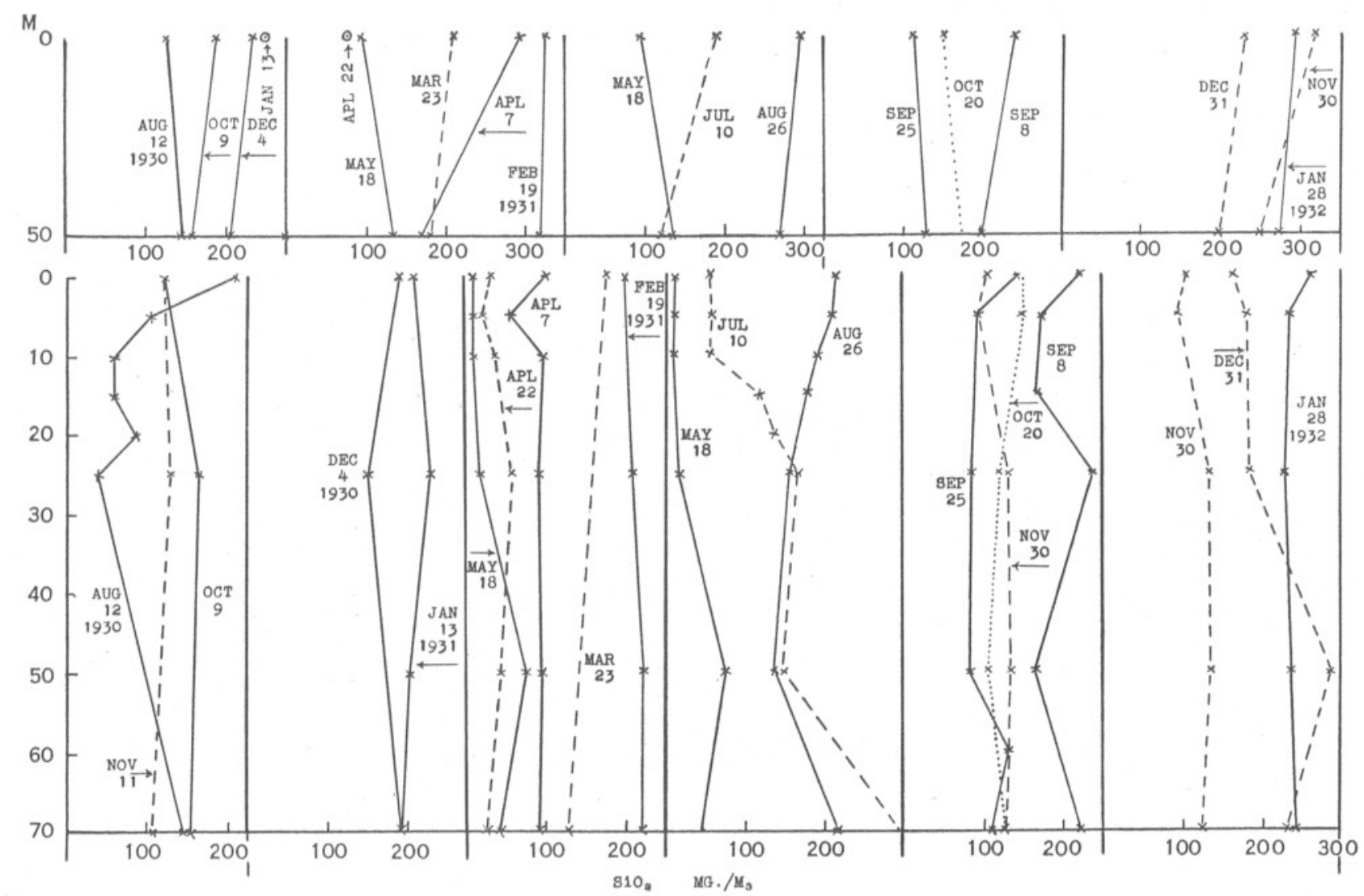

FIG. 3.-Profiles showing variation of silicate with depth at Stations L4 and E1, August, 1930, to January, 1932. The depth seale for L4 (top) is half that for EI (bottom). The spring consumption by diatoms is clearly shown in the third El panel. The high values and the distribution during. July to September appeared to indicate regeneration of silicate in the bottom 20 metres, followed by consumption of silicate throughout the column. All values are correct according to King and Lucas' standard. 


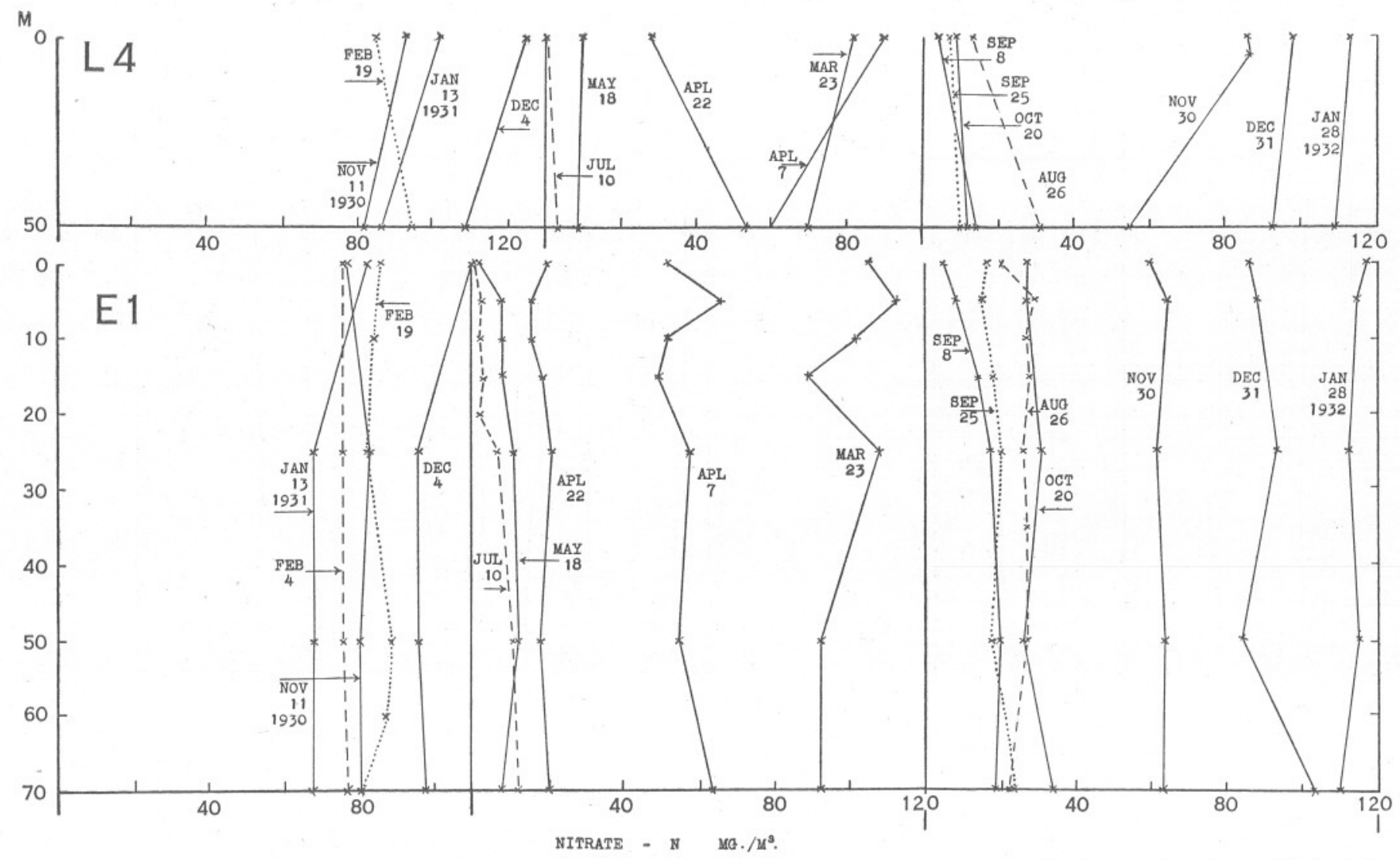

Fig. 4.- Profiles showing variation in nitrate (including nitrite) with depth November, 1930-January, 1932. The depth scale for L4 (top) is half that for El (bottom). Two maxima were reached on December 4th, 1930, and March 23rd, 1931. The results for December 31st, 1931, and January 28th, 1932, are approximate only. 
The main outburst, however, started about the beginning of March and went on, probably, until the end of May. For the fifteen days from March 7 th to March 22nd the average daily sunshine was $5 \cdot 25$ hours and accompanied marked decrease in phosphate. A

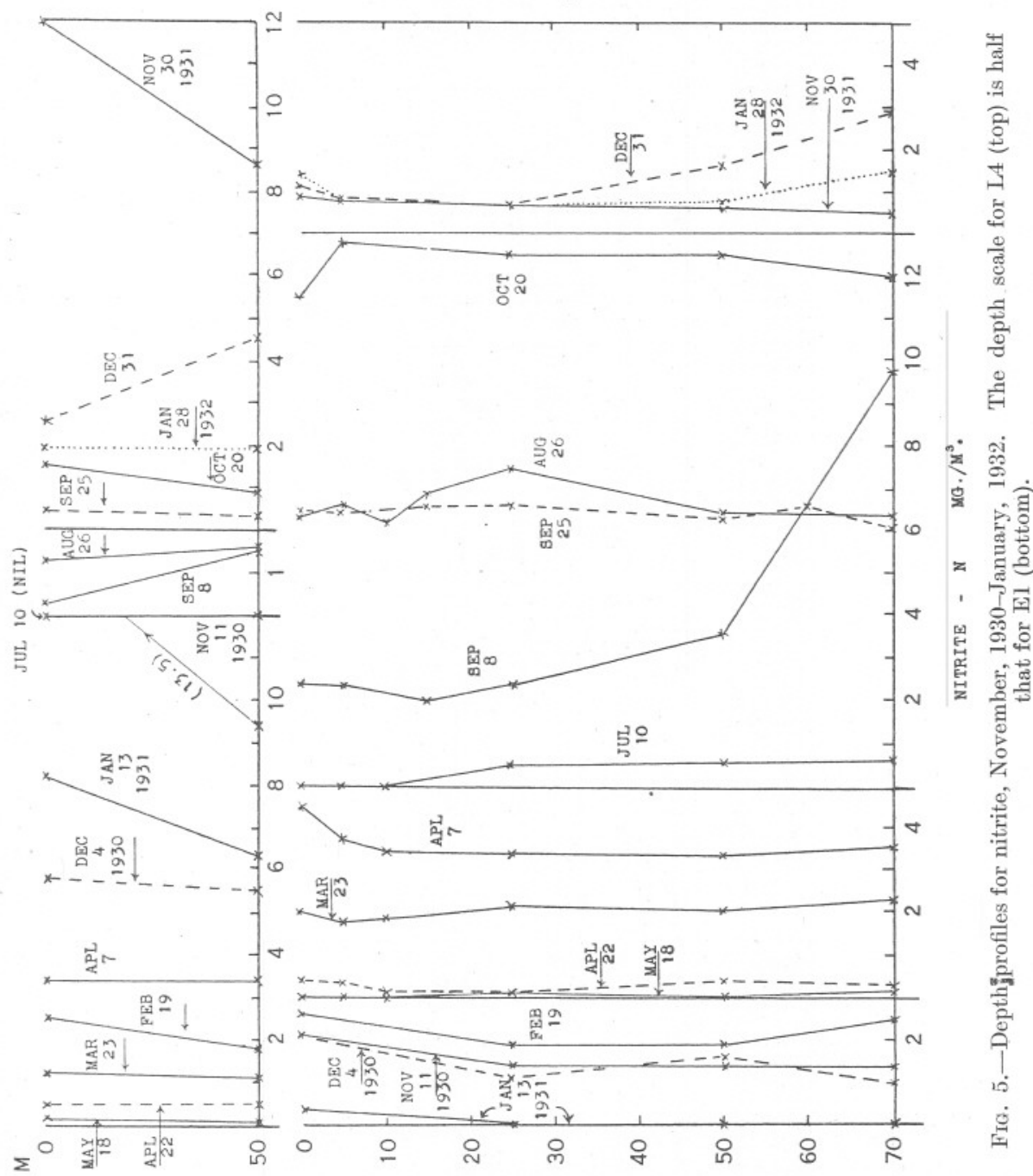

"static" condition existed between March 23rd and April 7th, when only one hour of sunshine per day was recorded. On March 23rd Dr. Lebour reported large quantities of the diatom, Biddulphia sinensis, in the tow-nettings taken at E1, and still greater quantities in the medium tow-net catch on April 7th. On this date plankton generally was 
very abundant in the E1 tow-nettings and Phæocystis in particular was very conspicuous in the sample bottles from 10 and 15 metres. With the return of bright sunshine further rapid depletion of the whole column took place. Thus 1931 was definitely an early year, and taking the changes in the water column as a whole it may be said to be the earliest year yet recorded at Plymouth, no doubt due to the exceptional amount of sunshine falling in
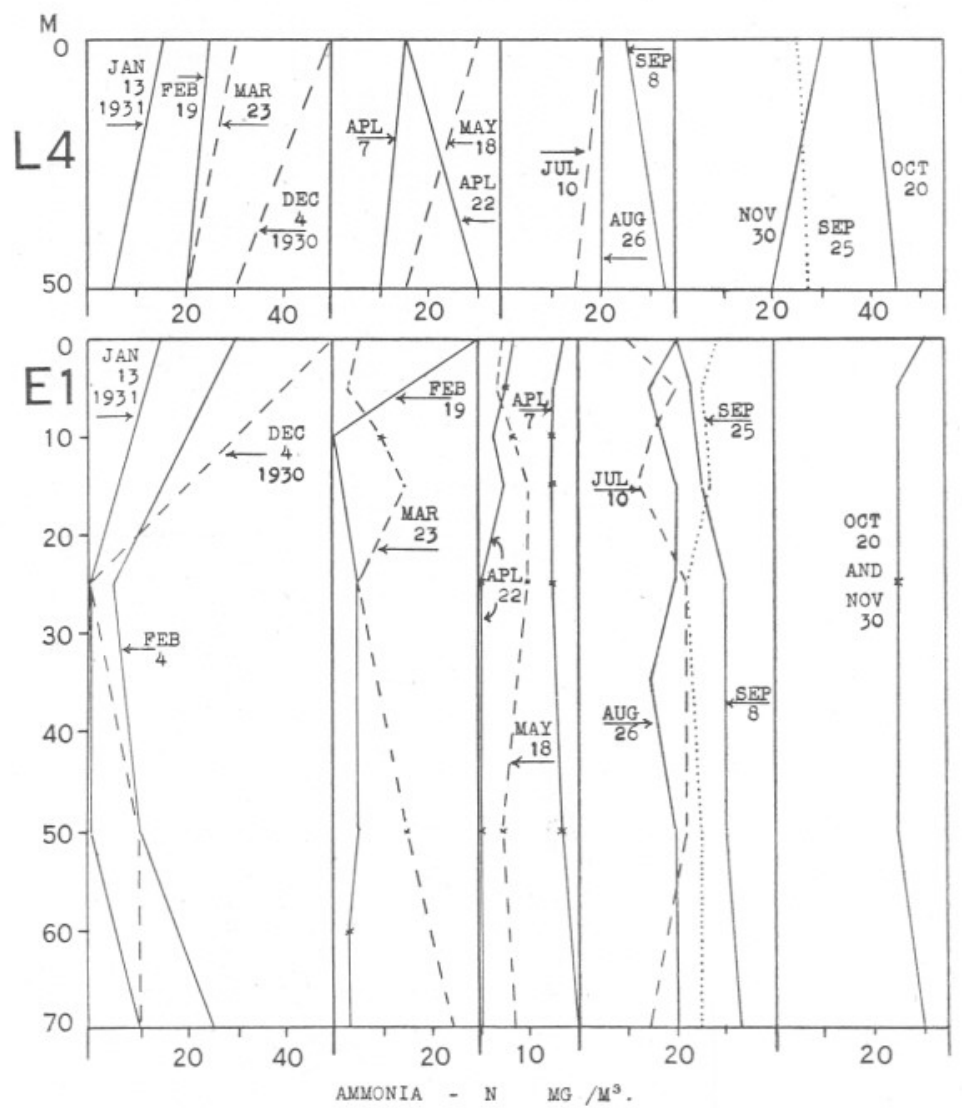

Fig. 6.-Depth profiles for ammonia, November, 1930-November, 1931. The depth scale for L4 is half that for El.

January. It was also remarkable for the efficiency with which the bottom store was brought to the illuminated regions and utilised. The nearest approach to the conditions of 1931 was found in the spring of 1924, but even in that year the bottom phosphate was usually $5 \mathrm{mg} . \mathrm{P}_{2} \mathrm{O}_{5}$ per cubic metre greater. The spring of 1931 is further notable for the absence of any period when regeneration definitely exceeded consumption.

The summer period of 1931 which may be said to begin at the end of 

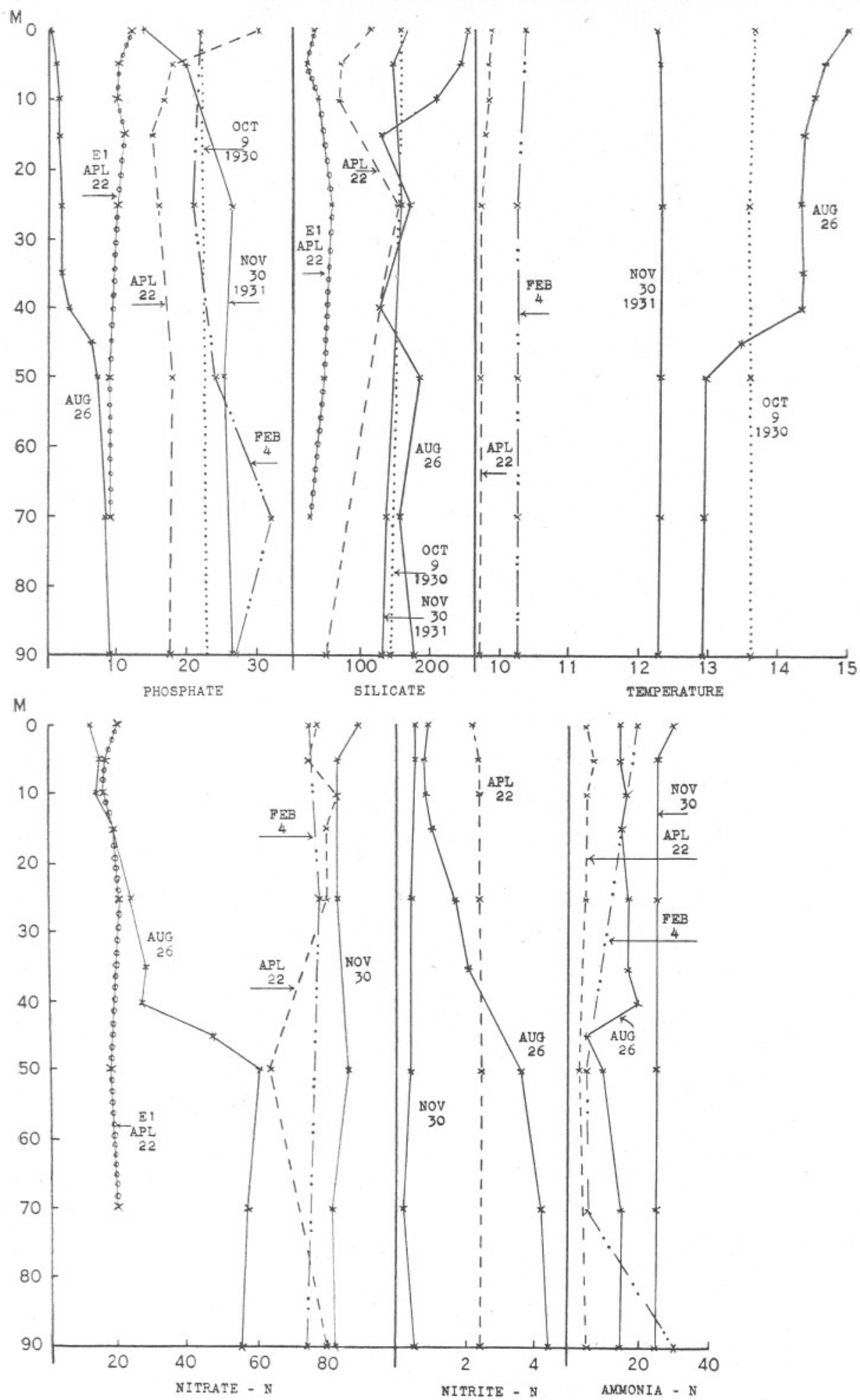

FIG. 7.-Station E2. Phosphate $\left(\mathrm{P}_{2} \mathrm{O}_{5}, \mathrm{mg} . / \mathrm{m}^{3}\right.$. $)$; Silicate $\left(\mathrm{SiO}_{2}, \mathrm{mg} . / \mathrm{m}^{3}\right.$. $)$; Temperature $\left({ }^{\circ} \mathrm{C}.\right)$; Nitrate, Nitrite, and Ammonia (each $\mathrm{mg}$. Nitrogen $/ \mathrm{m}^{3}$.). Curves for El (circles) are included for $\mathrm{P}_{2} \mathrm{O}_{5}, \mathrm{SiO}_{2}$, and nitrate for April 22nd for comparison with those for $\mathrm{E} 2$ on this date (pecked). 
May was also unique and was undoubtedly affected by the stormy and sunless weather experienced. The spring diatom outbreak had left the bottom waters very poor in phosphate (5 mg. on May 18th). A little regeneration took place at the bottom during June, but this was in no way comparable with that which has taken place in some previous years, e.g. 1925. The surface content did not fall below $5 \mathrm{mg} . \mathrm{P}_{2} \mathrm{O}_{5}$ per cubic metre until some time in August, but on August 26th the whole column was almost entirely depleted with $2 \mathrm{mg}$. in the surface and $4 \mathrm{mg}$. in the bottom layers. This depletion was probably facilitated by the very early breakdown of the thermocline in August (Fig. 1) due to the exceptionally stormy weather of mid-August. The average phosphatecontent of the water column*-2.8 mg. $\mathrm{P}_{2} \mathrm{O}_{5}$-was by far the lowest yet recorded. The next lowest figures are $5 \cdot 1 \mathrm{mg}$. on August 31st, 1925, $6.9 \mathrm{mg}$. on July $8 \mathrm{th}, 1925$, and $7 \cdot 7 \mathrm{mg}$. on July 10th, 1923. Indeed, average contents less than $9 \mathrm{mg}$. are comparatively rare, and are usually isolated occurrences in the course of a summer. In 1931, by contrast, the average value remained continuously at or below $7 \mathrm{mg}$. from May 18th to August 26th. But it should be pointed out that owing to a combination of circumstances, principally bad weather, only one cruise - that on July 10th-was made between these dates, so that a period of regeneration might have occurred and not have been observed. In 1925 there were periods of regeneration when the phosphate content of the bottom water rose to over $20 \mathrm{mg}$. $\mathrm{P}_{2} \mathrm{O}_{5}$ per cubic metre. In none of the five former summers for which data are available has any comparable period of low bottom phosphate been found. Comparison with Atkins' papers is informative.

Between August 26th and September 8th, marked regeneration set in, particularly at the bottom, and the average content of the water column increased from $2 \cdot 8 \mathrm{mg}$. to $10 \cdot 6 \mathrm{mg}$. $\mathrm{P}_{2} \mathrm{O}_{5}$ per cubic metre. In September and October a state of balance existed, consumption of phosphate just equalling regeneration. Absence of sunlight does not explain the regeneration found in the first week of September as Table II shows (compare also Section V).

TABLE II. Relation between changes in Phosphate and Nitrate and
Sunshine in the early Autumn of 1931.

1931.

$26 / 8$ to $7 / 9$

$8 / 9$ to $24 / 9$

$25 / 9$ to $19 / 10$

$\begin{array}{cc}\begin{array}{c}\text { Change in Average } \\ \text { Change in Average } \\ \text { Phosphate Content } \\ \text { pent of Nitrate } \\ \text { (and Nays, }\end{array} & \begin{array}{c}\text { (antrite) } \\ \text { per } 7 \text { days, }\end{array} \\ \begin{array}{cc}\mathrm{P}_{2} \mathrm{O}_{5} \text { per } \mathrm{m}^{3} \text {. } & \text { mg. N per } \mathrm{m}^{3} . \\ +4 \cdot 2 & -5 \cdot 3 \\ -0.6 & +1 \cdot 1 \\ +0.25 & +3 \cdot 0\end{array}\end{array}$

Change in Average Content of Nitrate

Average Daily Phosphate Content (and Nitrite) Sunshine per 7 days, per 7 days, in Hours. $4 \cdot 6$ $4 \cdot 9$ $2 \cdot 7$

* For the method of arriving at this quantity see p. 722 . 
There must therefore have been some other factor, probably nitrate, hindering the re-utilisation of the phosphate as it was returned into circulation. As soon, however, as sufficient nitrate became available, phosphate was utilised as quickly as it was re-formed, and a state of balance was set up which persisted even with the reduced October sunshine (see p. 701). During November consumption became unimportant

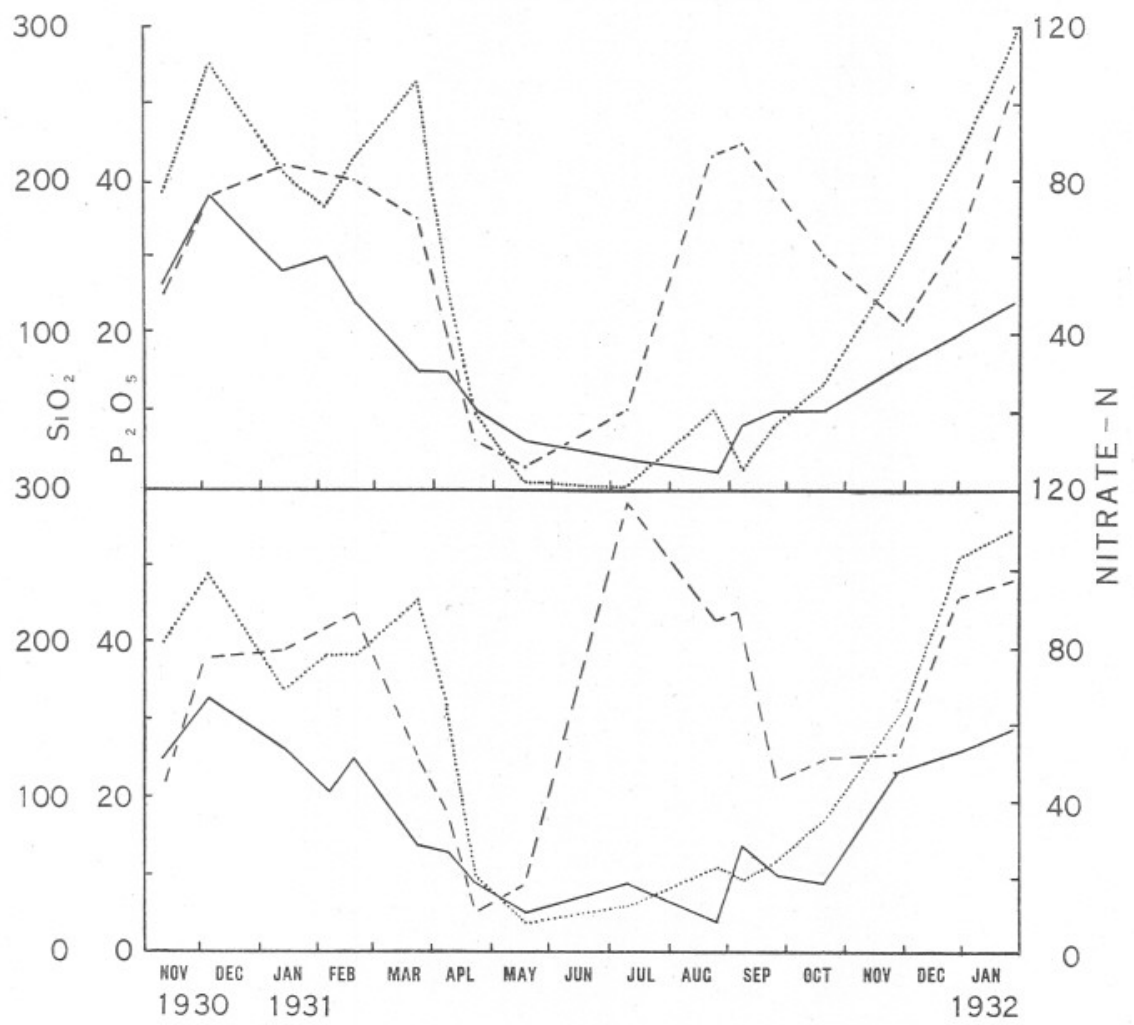

FIG. 8.-Phosphate, silicate and nitrate at Station El during 1931. Phosphate as $\mathrm{P}_{2} \mathrm{O}_{5}$ (full line), silicate as $\mathrm{SiO}_{2}$ (pecked), nitrate (which includes nitrite) as N (dotted), in each case $\mathrm{mg}$. per $\mathrm{m}^{3}$. The lower portion depicts the changes at the bottom, the upper those at the surface, except that for phosphate, $5 \mathrm{~m}$. values are plotted for April 7th and 22 nd.

and regeneration proceeded apace. During the next two months covering the period in which the maximum is usually reached, there was little further change in the water column, although the surface content of phosphate increased, becoming uniform with the rest of the column. If the figures for January 28th, 1932 ( $24 \cdot 7 \mathrm{mg}$.), really represent the winter maximum, this is the lowest on record. The previous lowest was on December 4th, 1930 , with $29 \cdot 1 \mathrm{mg}$. of $\mathrm{P}_{2} \mathrm{O}_{5}$ per cubic metre. 


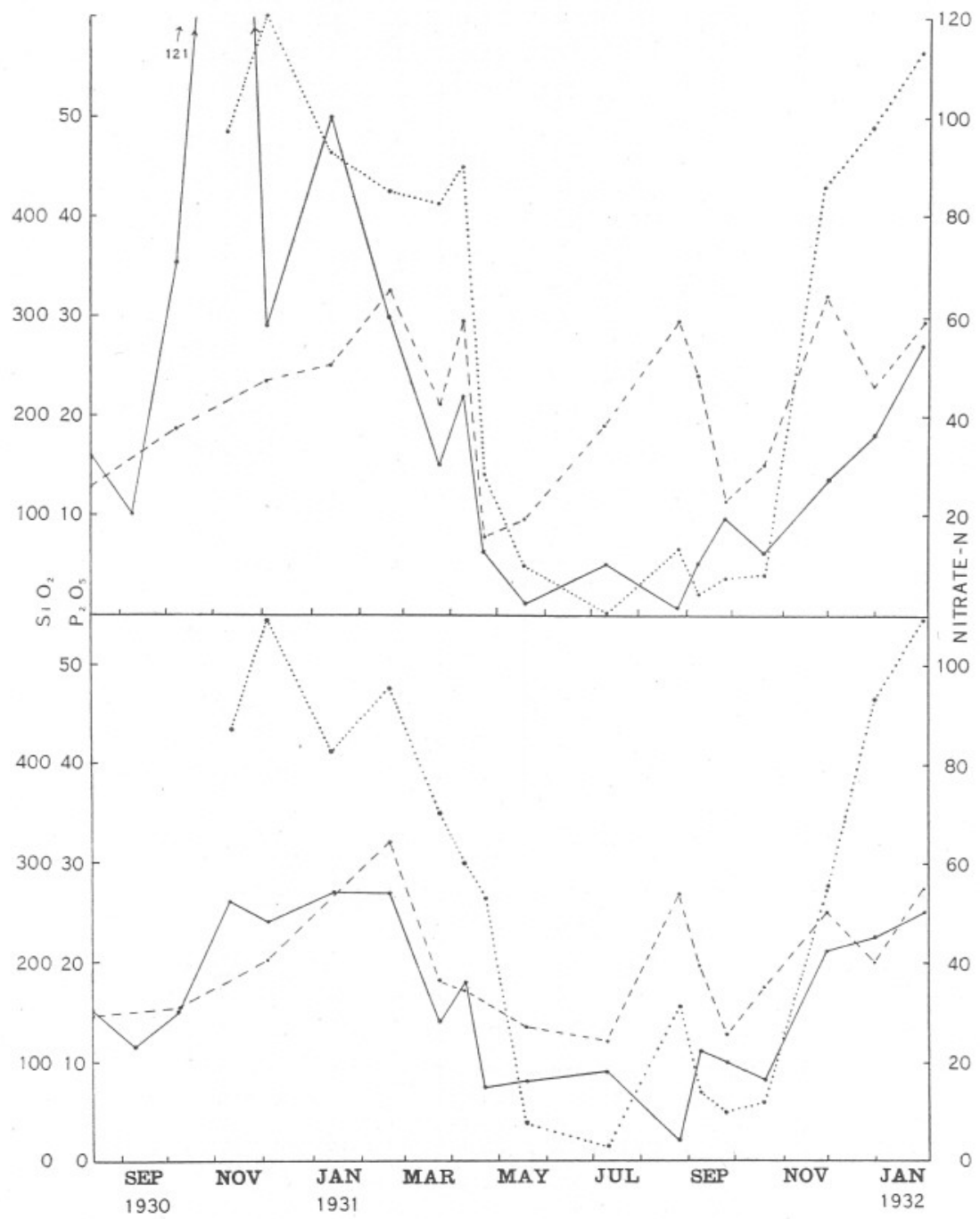

FIG. 9.- Seasonal variation at surface (upper half) and bottom (lower half) at Station L4 of phosphate (full line), silicate (pecked line), and nitrate (+nitrite) (dotted line), as $\mathrm{P}_{2} \mathrm{O}_{5}, \mathrm{SiO}_{2}$, and $\mathrm{N}$, mg. $/ \mathrm{m}^{3}$. August 12th, 1930, to January 28th, 1932. 


\section{Station L4.}

The picture of events here presents some points of difference from that at E1 (cf. Figs. 2 and 9). On November 11th, 1930, and January 13th, 1931, figures were obtained for the surface greatly in excess of those for the bottom and probably represent decomposition of organic matter occurring on the surface, an effect not extending to any depth. The bottom figures are therefore a more reliable guide to the true general behaviour of phosphate and point to the winter maximum being around $27 \mathrm{mg} . \mathrm{P}_{2} \mathrm{O}_{5}$ per cubic metre in January, compared with $29 \mathrm{mg}$. at E1 in early December. The start of the spring outburst cannot be fixed with certainty, but probably occurred in the middle of February. Marked regeneration took place in the sunless period between March 23rd and April 7th when El showed little change. From then on until October events followed much the same course as at E1, but subsequently regeneration at $\mathrm{L} 4$ proceeded rather the more slowly until the end of the year.

\section{Stations E2 and E3.}

In October, 1930, when regeneration at the L surface stations was proceeding rapidly, conditions at E2 (Fig. 7) were found to be very similar to those at E1 with $22 \mathrm{mg} . \mathrm{P}_{2} \mathrm{O}_{5}$ per cubic metre throughout the water column. The lower surface figures at E2 on the cruise of February 4th--5th, 1931, indicated that an outburst of diatom growth had begun there, but not at E3 which showed uniform distribution throughout the column. On April 22nd an interesting picture is presented. At L4 and E1 the phosphate was distributed uniformly from 5 metres to the bottom with $10 \mathrm{mg}$. $\mathrm{P}_{2} \mathrm{O}_{5}$ per cubic metre or less. At E2, however, about $17 \mathrm{mg}$. remained distributed throughout the column and very marked regeneration was proceeding at the surface. Nitrate was also much greater at E2 than at E1 (p. 703), so that the early start in consumption by diatoms made at E2 in February was evidently not maintained.

Visual examination of the sample bottles drawn on April 22nd and the rate of clearing in the horizontal comparison tubes during the course of the silicate analyses, also showed plankton to be much less abundant at E2 than at E1.

The distinctive behaviour of Stations E1 and E2 is a regular event (cf. Table III). In five out of six years the outbreak has started earlier at E2 than at E1. Yet in April-May phosphate was usually decidedly higher at E2 than at E1 and in no year was it definitely lower. Nitrate is not a reliable guide to crop production in the early spring, but the data available for 1926 and 1931 show the same relation. The outbreak therefore tends to start earlier at E2 in mid-Channel than at E1, but for 
some reason the early start is not maintained. By the middle of May E1 has/shown much the greater production.

\section{TABLE III.}

Phosphate Content of the Water found on the First and Second Cruises of the year to E2 AND E3.

Average values over six years (1924, '25, '26, '27, '28, '31). The year 1929 is excluded since the cruises were six weeks or more earlier than in the other years. Actual number of observations in parenthesis. $\mathrm{P}_{2} \mathrm{O}_{5}$, $\mathrm{mg} \cdot / \mathrm{m}^{3}$.

Period Feb. 4-March 11.

E1 Midway E2 Midway E3

0 metres

5 metres

Average content of water column
$29(6) \quad 22(4) \quad 16(6) \quad 12(3) \quad 20(6)$

$31(4) \quad-\quad 25(4) \quad-\quad 28(3)$

$30(6)-26(6)-26(6)$
Period April 22-May 21. E1 Midway E2 Midway E3

$6(5) \quad 7(3) \quad 15(5) \quad 17(3) \quad 17(4)$

$9(5)-14(4) \quad-\quad 25(2)$

$12(5) \quad-\quad 17(5)-25(4)$

The surface at E2 in late August, 1931, was almost completely exhausted of phosphate although greater reserves remained in the bottom waters at E2 than at E1. This no doubt is connected with the persistence of a thermocline at E2 after the August gales, although very deep at 45 metres (cf. Figs. 1 and 7). On November 30th regeneration had reached a similar stage to that at E1. Surface values at L4, E1, Midway Station, and $\mathrm{E} 2$ were all 5.5-7 mg. $\mathrm{P}_{2} \mathrm{O}_{5} / \mathrm{m}^{3}$ lower than those at 5 metres, pointing to a very late continuance of diatom growth in the surface layers right across the Channel.

\section{Differential Method of Representing Intensity of Plankton Outbursts in Terms of Change in Phosphate.}

Atkins (1930, Figs. 4, 5, and 6) suggested graphical methods of following the intensity of utilisation of phosphate. By the method of Fig. 10, both total consumption and rate of consumption between two cruises may be shown simultaneously as explained in the legend. The effect of the time elapsing between the cruises may thus be eliminated. In 1928 frequent cruises were made in connection with the work on illumination, whereas in 1926 they were about a month apart. The spring of 1926 was characterised by periods of excessive consumption with intervening periods of marked regeneration, quite different from the spring of 1931 when regeneration never exceeded consumption. The period of phosphate regeneration in the first week of September, 1931, is shown to have been very marked. 


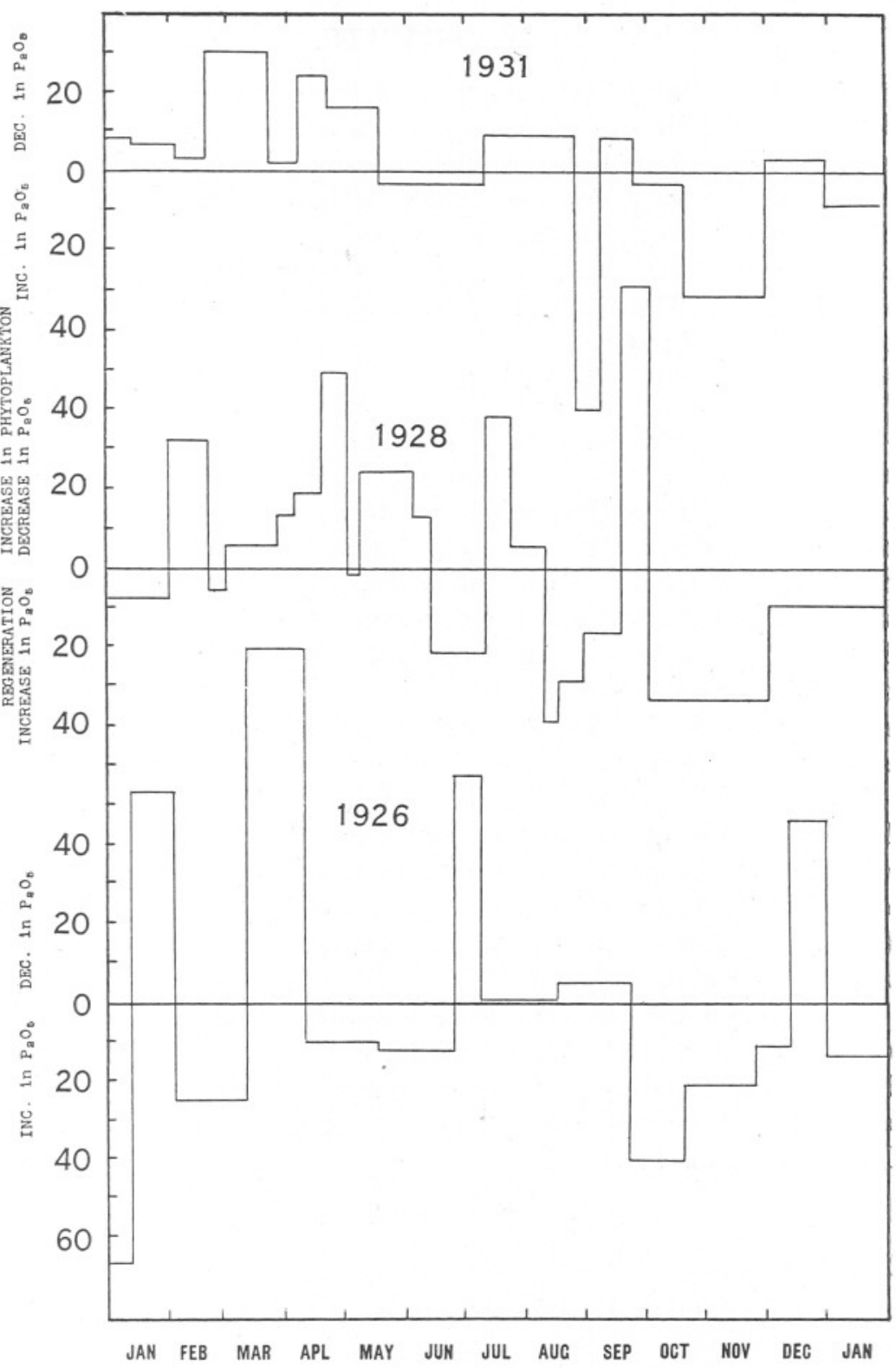

FIG. 10.-The production of phytoplankton at Station El may be deduced from the areas above the zero line. These really show the decrease in average phosphate concentration of the water column between two successive cruises. The height of the horizontal boundary line is a measure of the intensity of the outburst and is measured as $\frac{\delta\left(\mathrm{P}_{2} \mathrm{O}_{5}\right)}{\delta \mathrm{t}}$, i.e. rate of change of phosphate in mg. $\mathrm{P}_{2} \mathrm{O}_{5}$ per 100 cubic metres per day. From data by Atkins (1928, 1930 ; see 1930, Figs. 4 and 5), and this paper. 


\section{SILICATE.}

Silicate was first determined in the waters of the English Channel by the present colorimetric method by Atkins (1923 (2)). Since then determinations have been made at intervals although less frequently and in less detail than for phosphate (Atkins, 1926 (1), 1928, 1930 (2)). In the more recent years surface and bottom determinations only were made. Since August, 1930, depth series as for phosphate have been taken in waxed bottles. The results (Figs. 3 and 8 ) show striking differences from the behaviour of phosphate.

\section{Station E1.}

Fig. 3 shows that the vertical distribution of silicate is by no means uniform even when the water column is isothermal. The progressive decrease during the spring period of diatom growth is also clearly shown, but between March 23rd and April 7th, when sunlight and phosphate both point to a halt in plankton production, silicate (and also nitrate) showed a very marked fall, the reason for which is not very clear. On May 18th the surface contained less than $15 \mathrm{mg}$. $\mathrm{SiO}_{2}$ per cubic metre, the minimum which can be detected by the method with any degree of certainty (see Section XI, Methods), so that the water was quite likely completely exhausted of silicate.

The very different state of affairs on July 10th is also shown by Fig. 3 . The remarkable dilution of the surface with fresh water was probably related to the heavy rainfall over South-West England during June and early July, leading to river water flowing out over the surface. Part of this seems to have mixed across the thermocline diluting somewhat the bottom water also.

Solution of bottom siliceous deposits seems to give the only reasonable explanation of the high values for silicate at the bottom, although land drainage may have been a contributory factor. The greater content of silicate in the bottom waters persisted in lessening degree until midOctober as Table IV shows.

TABLE IV.

Illustrating the much greater Silicate Content of Bottom Water COMpared With that of WATER 20 metres ofF the Bottom in Summer and Autumn.

\begin{tabular}{|c|c|c|c|c|c|c|c|}
\hline & & 1930 & 1931 & & & & \\
\hline & & $12 / 8$ & $10 / 7$ & $26 / 8$ & $8 / 9$ & $25 / 9$ & $20 / 10$ \\
\hline & $50 \mathrm{~m}$. & $38 *$ & 148 & 136 & 165 & 83 & 105 \\
\hline $\left.\mathrm{SiO}_{2} \mathrm{mg} \cdot / \mathrm{m}^{3}\right\}$ & Bottom (68-71 m.) & 145 & 291 & 213 & 221 & 111 & 125 \\
\hline & Difference & +107 & +143 & $\begin{array}{r}+77 \\
-0.05\end{array}$ & $\begin{array}{r}+56 \\
\end{array}$ & +28 & +20 \\
\hline 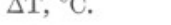 & & $-0.07 *$ & -0.18 & -0.05 & -0.02 & 0.00 & $0 \cdot 00$ \\
\hline
\end{tabular}

\footnotetext{
* $25 \mathrm{~m}$. No analysis for $50 \mathrm{~m}$.
} 
There is no direct correlation with the dilution with river water which was primarily a surface phenomenon.

The difference in temperature in the bottom 20 metres on July 10th was only $0 \cdot 18^{\circ}$, and after August 26th it practically vanished, so that there was little hindrance to vertical mixing. A similar distribution was also present in August, 1930. Such great differences in the silicate content of the water within 20 metres from the bottom seem very strong evidence in favour of purely chemical re-solution of the siliceous bottom deposits. It is, of course, possible that this re-solution goes on the whole year round, but that it is most evident in late summer owing to the stability of the layers under the thermocline.

Regarding the water column as a whole, silicate is seen to suffer a very unequal distribution in the late summer and early autumn (Fig. 3). Although the average values for the column on July 10th, August 26th, and September 8 th $\left(154,168,154 \mathrm{mg}\right.$. $\mathrm{SiO}_{2} / \mathrm{m}^{3}$. respectively) were similar, the distributions were quite different. A great increase took place at the surface during August, 1931, and at 25 metres between August 26th and September 8 th. These increases are much greater than the experimental error and indicate that re-solution of silicate may occur not only at the bottom but on a lesser scale at the surface and in the middle layers as well. More detailed data are required to establish the point, but these erratic results are probably correlated with the position in the water of the dying and dead diatoms. If these are especially copious around, say, 25 metres, re-solution will occur most rapidly there and a silicate maximum will be observed.

The large decrease in the middle of September, during a period when the balance of consumption and regeneration of phosphate and nitrate remained undisturbed and sunlight was adequate for photosynthesis, suggests an autumn diatom outburst. The distinctive behaviour of the three salts is a little mystifying. An explanation probably requires detailed knowledge of the plankton species propagating at the time. Nevertheless, a steady state for phosphate in the autumn may indicate a diatom outbreak as clearly as a definite decrease in the spring, owing to the more extensive simultaneous regeneration of phosphate.

\section{The Summer Maximum for Silicate. Mechanism of Re-solution of Silica in the Sea.}

The seasonal change in the silicate content of surface water at E1 in different years is illustrated by Fig. 11. In each spring there has been a rapid decrease associated with the diatom outburst. The great differences in the winter maximum discussed below are clearly shown, whilst in 1924, 1925, 1930, and 1931 marked regeneration of both surface and bottom 


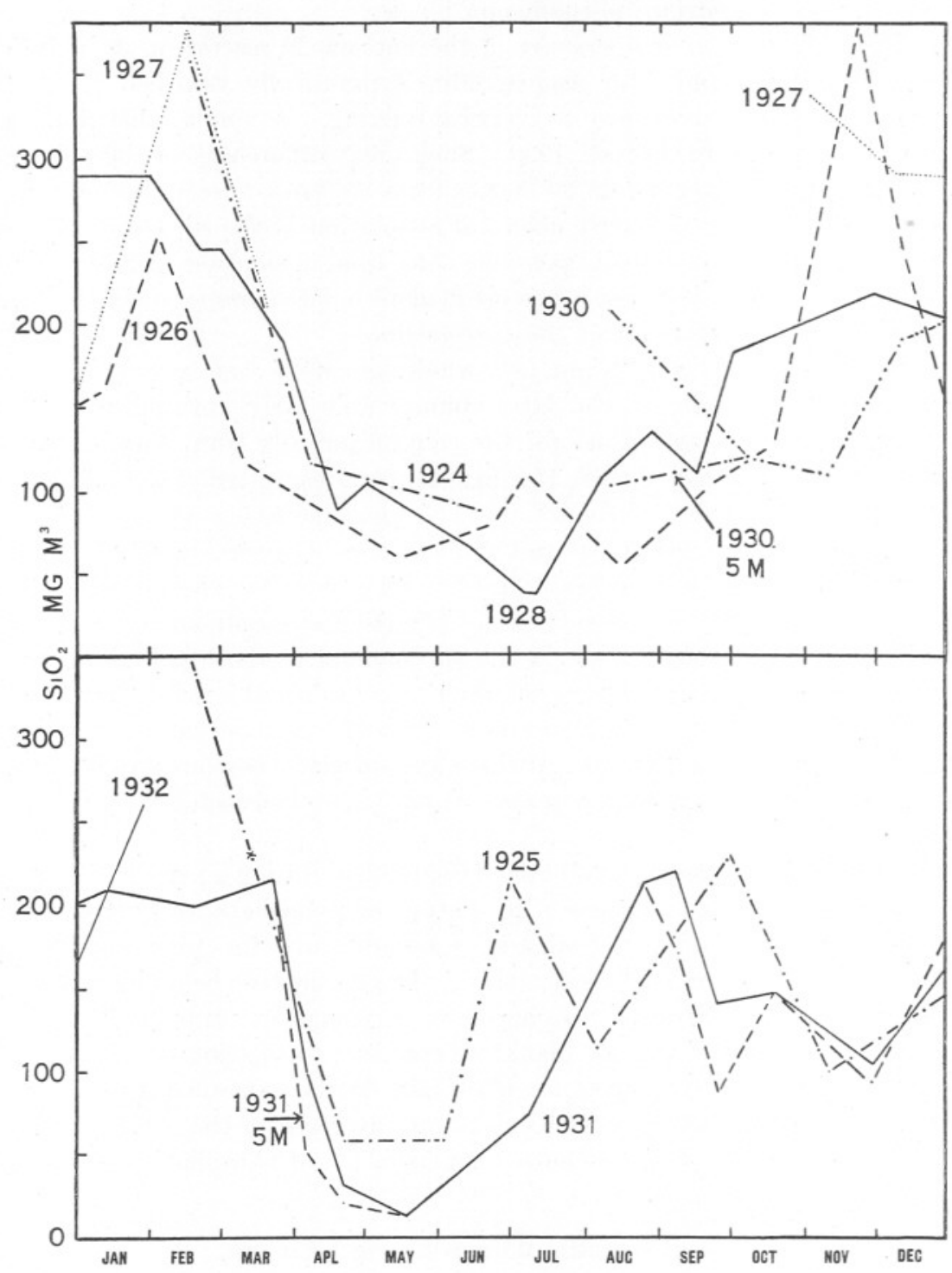

FIG. 11.- Seasonal variation in the silicate content of surface water at E1. Curves for 1924-29 constructed from Atkins' data ; for 1930-31 from data in this paper. The curves for bottom water (not published) are, on the whole, similar with a tendency for greater concentration of silicate in spring and early summer than at the surface. $\mathrm{SiO}_{2}, \mathrm{mg} \cdot / \mathrm{m}^{3}$. 
silicate occurred during the summer months. In 1925, the silicate maxima were not simultaneous with the phosphate maxima observed at the bottom. However, the values for August 12th, 1930, show that comparatively high surface and bottom values may be found when the middle layers are nearly exhausted of silicate. In this case the surface and bottom values taken alone would give a quite erroneous picture of the state of the water column as a whole. Nevertheless, it can scarcely be fortuitous that very definite increases at surface and bottom have been observed in three out of the four summers for which data are available.

At first sight it seems scarcely possible that the siliceous tests of diatoms dying off after the spring outburst can be so quickly re-dissolved; yet this is the conclusion to which the above discussion leads. But inasmuch as the siliceous skeletons offer an enormously greater surface to the solvent action of the somewhat alkaline sea-water ( $\mathrm{pH}$ about 8.2$)$ than, say, an equal weight of sand grains, such rapid resolution seems a sound explanation of the results. Of this Miss Stanbury's observations (1931) in this Laboratory of the rapidity with which skeletons of dead diatoms may disappear in culture experiments afford confirmation.

Such dissolution of silica may occur not only from dead diatom skeletons. Bachrach and Lefèvre $(1928,1929)$ have observed the complete loss of the external skeletons from a number of living plants reared on sterilised media even in the presence of silicate. The $\mathrm{pH}$ of their media is not discussed. The genera most susceptible to this peculiar behaviour are Nitzschia, Navicula, Fragilaria, and Licmophora. The removal of the siliceous skeleton may require weeks or only a few days. The defective diatoms appear to live and reproduce quite normally although after a few generations they become so shapeless that identification is impossible. This work points to the rapidity with which the skeletons may dissolve in sea-water and to the possible adaptability to shortage of silicate of diatoms leading an otherwise normal life in the sea. The $\mathrm{pH}$ of the water is almost certainly of prime importance.

There is another way in which the occurrence of diatoms appears to be a function of the amount of silicate present. For the spring of 1932 no chemical data are available, but by analogy with other years silicate may be assumed to be plentiful in March and scarce in May. On March 21st Dr. Lebour found Coscinodiscus granii and Bacillaria paradoxa (normally an inshore form) to be predominant constituents of the tow-nettings taken beyond the Eddystone, whereas on May 26th, Cerataulina were very plentiful. There is thus a direct relation with the available silicate, since the March forms are thick walled and the May diatom thin walled, requiring relatively little silica.

According to N. Peters (1932), in the South Atlantic short-horned, robust Ceratia were found in waters rich in phosphate and plankton and 
long-horned, fragile forms in phosphate poor water. The phenomena may be a direct function of phosphate or possibly of another nutrient salt (such as (?) silicate).

During September, with isothermal conditions prevailing, there seems to have been extensive utilisation of silicate by an autumn outburst of diatoms, although phosphate remained steady and nitrate showed only a small fall. Subsequently, until January 28th, when observations ceased, there was a steady rise to about $235 \mathrm{mg}$. $\mathrm{SiO}_{2}$ throughout the water column.

\section{Increase in Silicate with Proximity to Shore.}

Determinations of silicate at the L Stations, other than L4, were not continued after October, 1930. The results obtained till then lend support to Atkins' conclusion (1926) that silicate due to land drainage increases rapidly on approaching a river mouth (Table V).

\section{TABLE $V$.}

Effect of River Water on Silicate Content of the Sea. High Silicate in the Sound is associated with the low Salinity AT Low Tide.

1930

August 12

October 9

August 12

October 9

State of Tide

$$
\text { at Ll. }
$$

Hours Ebb. L1. L2. L3. L4. L5. L6. E1. E2.

Silicate $\mathrm{SiO}_{2} \mathrm{mg} \cdot / \mathrm{m}^{3}$

\section{0}

$132 \quad 176 \quad 127$

600

$520-188$

155

$\begin{array}{llll}185 & 167 & 122 & 159\end{array}$

Salinity $\%$

$\begin{array}{llllllll}33.95 & 34.47 & 34.90 & 34.91 & 35.01 & 35.03 & 35.00 & -\end{array}$

$\begin{array}{llllllll}29 \cdot 25 & 32 \cdot 50 & 33 \cdot 83 & 35 \cdot 00 & 35 \cdot 03 & 35 \cdot 14 & 35 \cdot 21 & 35 \cdot 26\end{array}$

\section{Station L4.}

The results at L4 (surface and bottom, $50 \mathrm{~m}$., only), although decidedly higher than at E1 due to proximity to land, showed on the whole a similar trend (Figs. 3 and 9). The maximum for the winter $\left(325 \mathrm{mg}\right.$. $\mathrm{SiO}_{2}$ per cubic metre) was reached on February 19th, here also at least a month later than for phosphate. The subsequent fall was followed by a rise contrasting with the simultaneous drop at E1, but concordant with the small increase in phosphate and with the deficient sunlight. The minimum for the year was found on April $22 \mathrm{nd}$ ( $77 \mathrm{mg}$. at the surface, no analysis of bottom water), so that the more inshore water was never so completely depleted as was the surface at E1 on May 18th. Here also summer

\footnotetext{
* 5 metres, 104 mg. ; 10 metres, 59 mg.
} 
regeneration took place leading to a summer maximum for the whole water column of $280 \mathrm{mg}$. per cubic metre on August 26th. From then until November 30th the results are concordant with those at E1. A secondary minimum was found at L4 only on December 31st, 1931.

\section{Station E2.}

On October 9th, 1930, and November 30, 1931, conditions were not very different from those at E1 (Fig. 7). On April 22nd, the E2 depth series was very erratic, and on the whole considerably greater than that for E1, thus agreeing with the higher phosphate and nitrate figures which showed the spring outburst of diatoms to have been much delayed at E2. The very different values found for $25 \mathrm{~m}$. and $89 \mathrm{~m}$. (bottom)-154 mg. and $50 \mathrm{mg}$. $\mathrm{SiO}_{2}$ per cubic metre-are worthy of remark although no water was available from waxed bottles for confirmatory analyses. For the interesting distribution of August 26th, the remarks made for E1 apply.

Thus the work at L4 and E2 fits in very well with the conclusions deduced for E1-that a summer silicate maximum may be expected about August and that the winter silicate maximum occurs about a month later than that for phosphate.

\section{NITRATE.}

Harvey's work (1926, 1928 (1) ) in the English Channel had established that nitrate fluctuations followed a seasonal course similar to that of phosphate (cf. Brandt and Raben (Brandt, 1916, 1927)). Maxima were recorded in two winters and minima around midsummer approaching complete exhaustion with intervening rapid depletion during the height of the spring outburst of diatom growth. The present work in every way supports the accuracy of this picture for the Channel.

\section{Station E1.}

Observations began on November 11th, 1930. Examination of the depth profiles (Fig. 4 and also Fig. 13) shows that a first maximum was reached on December 4, but onwards until mid-January a decrease correlating with the decrease in phosphate was found. Regeneration of nitrate then proceeded apace, and a second maximum was reached on March 23rd when phosphate and silicate were well on the downward slope (cf. Fig. 8).

That plankton was present in quantity on this date was further indicated since the nitrate analyses were possible only after the samples had first been centrifuged (Cooper, 1932). Thus nitrate continued to increase when the diatom outburst was well under way.

The course of events between March 23rd and April 7th is not at all 
clear. Sunshine averaged only one hour per day, phosphate remained almost unchanged, yet the average content of nitrate-nitrogen throughout the water column fell by $40 \mathrm{mg}$. per cubic metre $(41 \%$ fall) and silicate by $60 \mathrm{mg}$. $\mathrm{SiO}_{2}(40 \%$ fall). There was little change in salinity or temperature so that no important water movements can have occurred.

A progressive fall in nitrate followed. On May 18th and July 10th, the

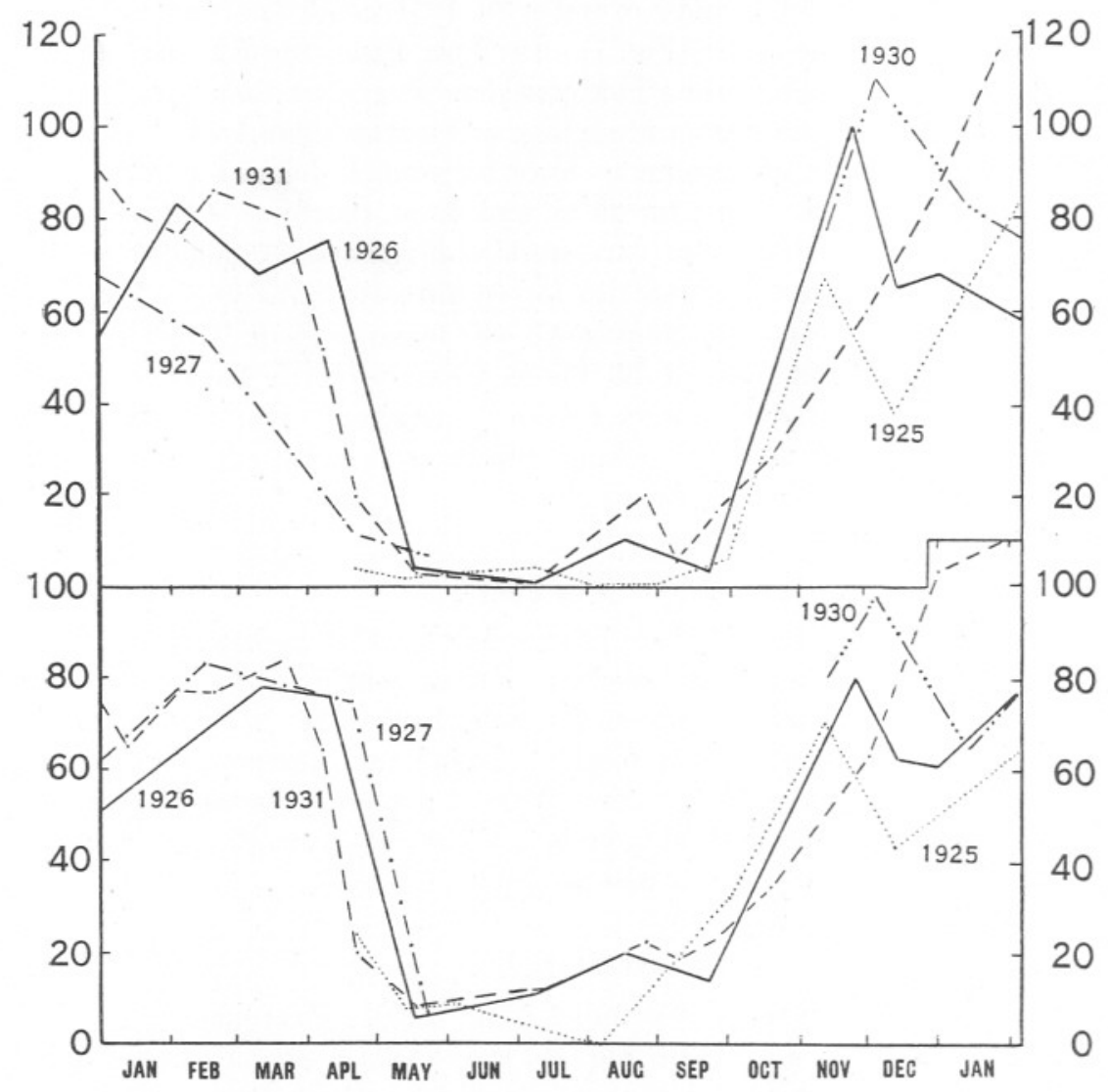

FIG. 12.-Comparison of the seasonal changes of nitrate (including nitrite) in 1930-31 with former years (Harvey). Upper portion, surface; lower portion, bottom; $\mathrm{mg} . \mathrm{N} / \mathrm{m}^{3}$.

surface was almost entirely depleted. There followed a gain in the whole water column in the rest of July and August of $14 \mathrm{mg}$. of nitrate-nitrogen per cubic metre after allowing for nitrite which also increased. During the same period phosphate decreased in the whole column to give a record low figure for phosphate.

In the first week in September, nitrate and phosphate again moved in opposite directions. The fall in nitrate fits in with that in mean silicate 
(14 mg. $\mathrm{SiO}_{2}$ ) and the plentiful sunlight ( $4 \cdot 6$ hours per day). It would seem that excessive regeneration of phosphate was masking its consumption by phytoplankton and that nitrate, since its return follows a long chain of chemical or bacterial reactions, is a more certain criterion of autumnal outbursts particularly if allowance can be made for nitrite (cf. Table II).

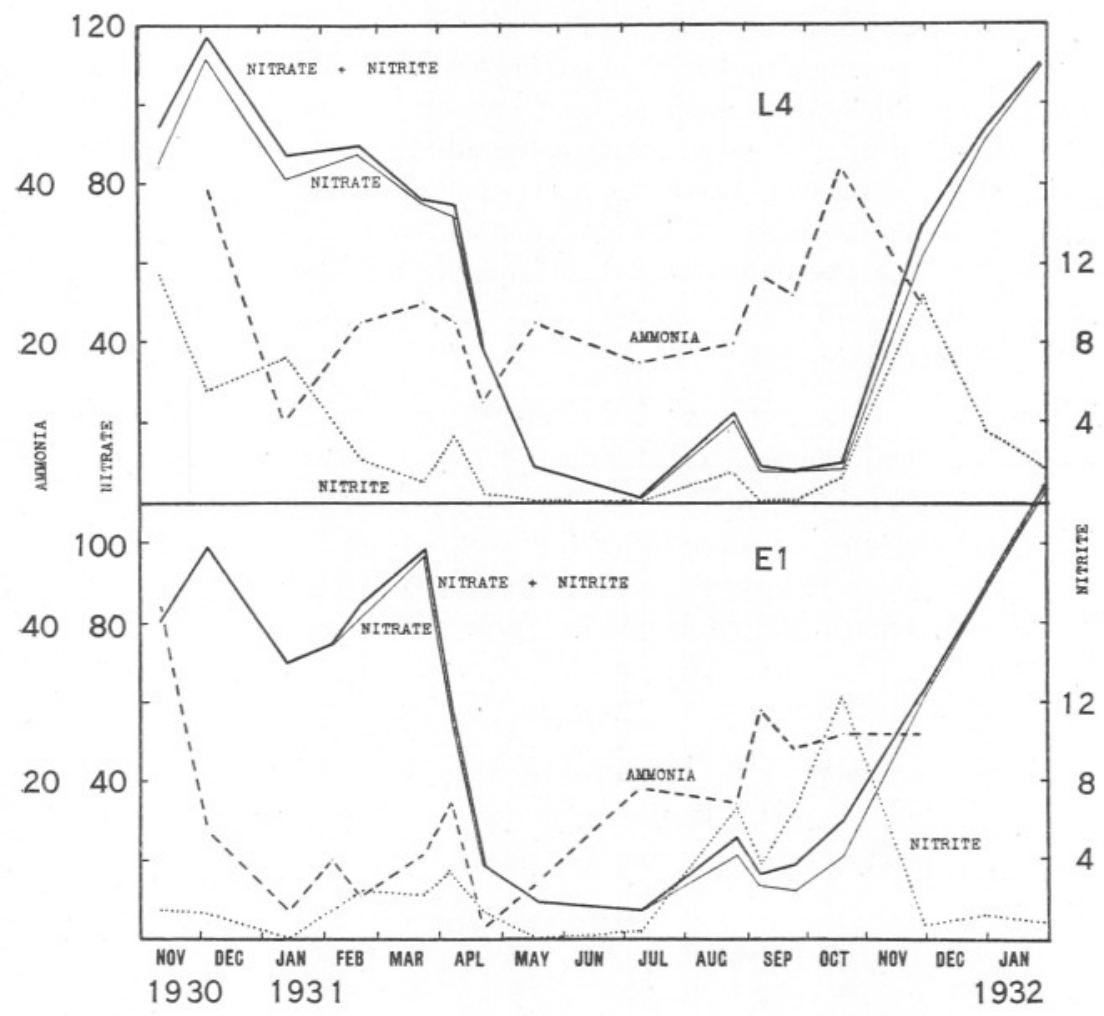

FIg. 13.- Seasonal changes in nitrogen compounds at Stations L4 and E1 between November, 1930, and January, 1932. Averages for the whole water column, all in $\mathrm{mg}$. nitrogen $/ \mathrm{m}^{3}$. The scales for nitrate, ammonia, and nitrite are in the ratio $1: 2: 5$. The thin line representing nitrate shows the effect of subtracting nitrite $(\times$ factor $0 \cdot 8$., see Cooper, 1932) from the results obtained with the reduced strychnine reagent (thick line) which also determines nitrite.

As with phosphate, down-grade processes did not finally get the upper hand till about the end of October.

In Fig. 12 the seasonal changes in nitrate at E1, surface and bottom, are compared with the corresponding results for previous years (Harvey, 1926, 1928). The fall in nitrate in the spring of 1931 followed a very similar course to that in 1926, although probably it occurred about a fortnight earlier. Both in 1926, between April 10th and May 17th, and in 
1931, between March 23rd and April 22nd, this fall in nitrate was very rapid and extended right to the bottom of the water column. Thus vertical circulation of the water must have brought the bottom store of nitrate rapidly into regions where it could be quickly utilised. The apparent utilisation of the available nitrate thus appears to be much more efficient than that of phosphate owing to the slower simultaneous regeneration of nitrate (see below).

In all three summers nitrate remained very low, but the rise in August, 1931, and subsequent drop is very similar to that in August, 1926. Regeneration in 1931 subsequently proceeded more slowly than in either of the former years ; nevertheless, at the end of January, 1932, the highest value-about $110 \mathrm{mg}$.- so far recorded at E1 was reached. Although the figures for December 31st and January 28th are only approximate, due to poor calibration curves, there can be no doubt that former maxima were exceeded.

\section{Station L4.}

The seasonal changes at.L4 (Figs. 4, 9 and 13) were, on the whole, similar to those at E1 with a tendency towards higher values in winter. There was only one maximum at this station-on December 4th, 1930.

The changes in the average nitrate and phosphate contents of the water columns at L4 and E1 are shown by Table VI.

\section{TABLE VI.}

Average Content of Phosphate and Nitrate at L4 and E1 in Winter and Spring of 1930-31.

\begin{tabular}{|c|c|c|c|c|c|c|c|c|c|}
\hline & $11 / 11 / 3$ & $4 / 12$ & $13 / 1 / 31$ & $4 / 2$ & $19 / 2$ & $23 / 3$ & $7 / 4$ & $22 / 4$ & $18 / 5$ \\
\hline & \multicolumn{9}{|c|}{ Nitrate, mg. $\mathrm{N}$ per $\mathrm{m}^{3}$} \\
\hline L4 & 95 & 118 & 87 & - & 90 & 76 & 75 & 40 & 9 \\
\hline E1 & $80 \cdot 5$ & 99 & 70 & 75 & 84 & $98 \cdot 5$ & 58 & $18 \cdot 5$ & 10 \\
\hline \multicolumn{10}{|c|}{ Phosphate, mg. $\mathrm{P}_{2} \mathrm{O}_{5}$ per $\mathrm{m}^{3}$} \\
\hline L4 & $>26$ & $26 \cdot 5$ & ca 38 & - & 29 & $14 \cdot 5$ & 20 & 7 & $4 \cdot 5$ \\
\hline E1 & 24 & 29 & 26 & 24 & $23 \cdot 5$ & $13 \cdot 8$ & $13 \cdot 5$ & $9 \cdot 8$ & $5 \cdot 5$ \\
\hline
\end{tabular}

There was thus no March nitrate maximum at L4 like that at E1. Further, whereas the main fall in phosphate began at the end of February or beginning of March, the related fall in nitrate was a month later at E1 and five weeks later at L4. Although at both stations in May the average nitrate content of the water column was about the same, the surface was less depleted at L4, the shallower and more inshore station, with $10 \mathrm{mg}$. of nitrate-nitrogen per cubic metre as against $2 \mathrm{mg}$. at E1. In the middle of July, by contrast, bottom nitrate was considerably higher at E1. Indeed, at L4 the very low bottom value of $3 \mathrm{mg}$. was then found. 
From then until end of the year events at the two stations followed a very similar course - a marked increase in August followed by consumption in September, little change in October and very rapid regeneration in November. The highest values were reached on January 28th, 1932, when observations ceased.

\section{Stations E2 and E3.}

On February 4th-5th the distribution at E1, E2, and E3 was almost identical within the limits of experimental error with $76 \mathrm{mg}$. nitratenitrogen throughout each water column. Signs of an early surface outbreak of phytoplankton at E2 as shown by phosphate determinations (p. 691) were thus lacking. The cruise of April 22nd revealed a strikingly different condition at E1 and E2. Whereas in the intervening twelve weeks average nitrate at E1 had fallen to $18.5 \mathrm{mg}$. nitrogen per cubic metre, the position at E2 was unchanged with $74 \mathrm{mg}$. remaining right through the water column (cf. Fig. 7). The comparable changes for phosphate were from 24 down to $9 \cdot 8 \mathrm{mg}$. at E1 and from 25 to $17 \mathrm{mg}$. at E2. Silicate in April also showed lower values at E1. Quite definitely, therefore, the diatom outburst up to the middle of April as inferred from chemical data was less intense in mid-Channel at E2 than at E1 (see p. 691).

\section{COMPARATIVE BEHAVIOUR OF NUTRIENT SALTS.}

\section{Seasonal Variation in Daily Consumption and Regeneration of Nutrient Salts.}

The differential method of representing change in mean phosphate outlined in Section III may be applied equally well to changes in mean silicate and nitrate (Fig. 14). For the six weeks preceding January 13th consumption of phosphate and nitrate was accompanied by slight regeneration of silicate. Right up to the middle of May consumption of phosphate exceeded regeneration and the general prevalence of growth processes in the sea during the whole period is supported by the silicate analyses and by various observations on the plankton (see Section III). Yet as late as March 23rd regeneration of nitrate was paramount. Nitrate must necessarily have been consumed in quantity during this period, but its reformation as the last process in the long nitrogen regenerative cycle must have been so pronounced as to obscure its consumption. Thus, during the first three months of the year, nitrate data alone would have given an entirely erroneous picture.

Nevertheless the fortnight immediately following March 23rd showed an absolutely different state of affairs. Net mean consumption of phosphate was trivial and there was actually an increase in phosphate at 


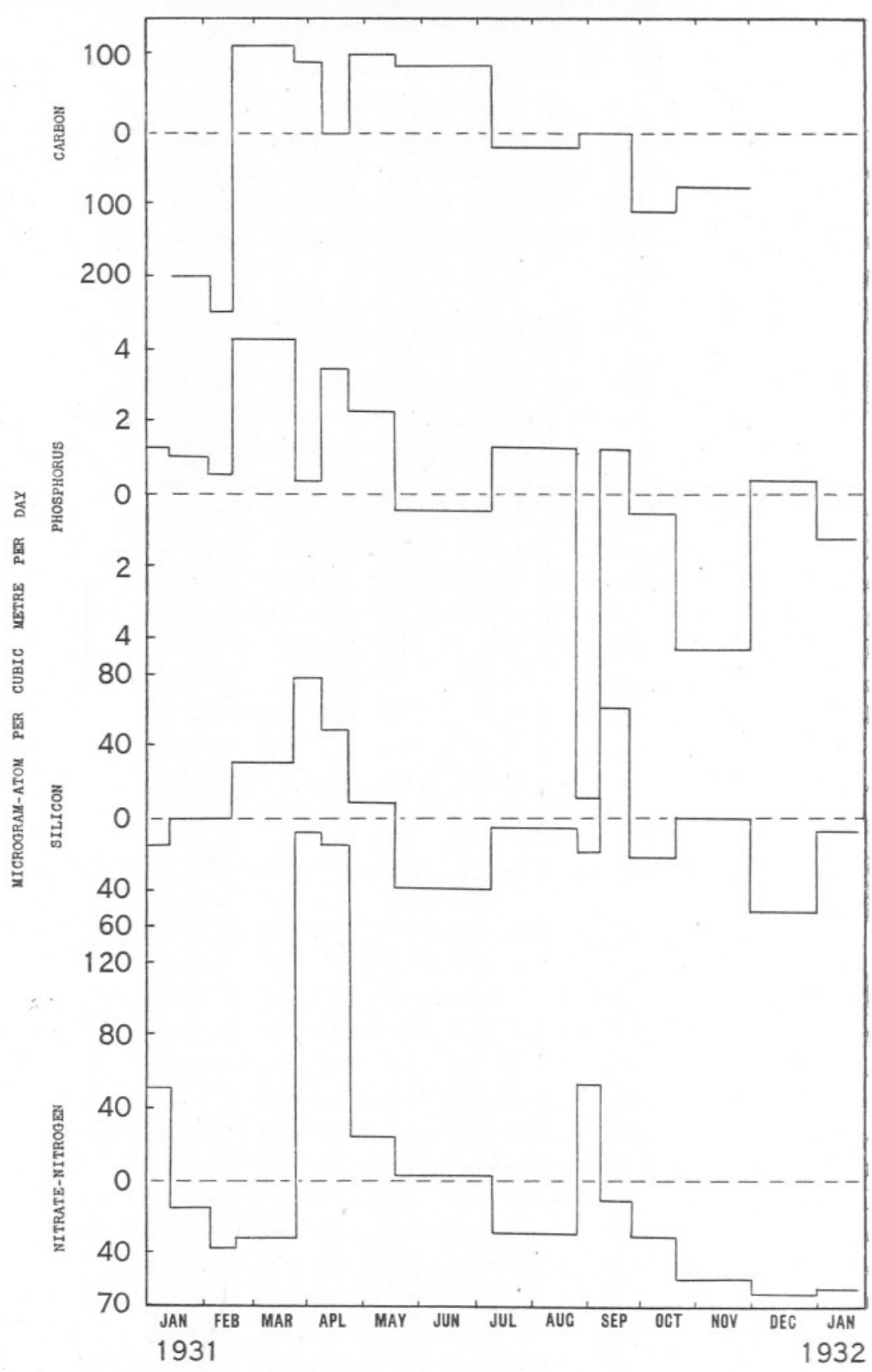

FIG. 14.-Daily consumption and regeneration of nutrient salts throughout the year. The area above or below the zero line represents total consumption or regeneration between successive cruises. The height of the horizontal represents rate of consumption or regeneration during the period, i.e. $\frac{\delta(\text { Salt })}{\delta t}$, the unit of salt concentration being the microgram-atom $\left(10^{-6}\right.$ gram-atom) of $\mathrm{P}, \mathrm{Si}, \mathrm{N}$, or $\mathrm{C}$, and the unit of time being the day. The ratio of the scales is:- $\mathrm{C}: \mathrm{Si}: \mathrm{N}: \mathrm{P}:: 1: 2 \cdot 5: 2 \cdot 5: 50$. Each diagram gives the atomic concentrations of $\mathrm{P}, \mathrm{Si}, \mathrm{N}$, and $\mathrm{C}$, or the molecular concentrations of $\mathrm{H}_{3} \mathrm{PO}_{4}$ (or $\frac{1}{2} \mathrm{P}_{2} \mathrm{O}_{5}$ ), $\mathrm{H}_{2} \mathrm{SiO}_{3}$ (or $\mathrm{SiO}_{2}$ ), $\mathrm{HNO}_{3}$ (or $\mathrm{N}$ ), and $\mathrm{CO}_{2}$, or the ionic concentrations of $\mathrm{PO}_{4}{ }^{\prime \prime \prime}, \mathrm{SiO}_{3}{ }^{\prime \prime}, \mathrm{NO}_{3}{ }^{\prime}$, and $\mathrm{CO}_{3}{ }^{\prime \prime}$. The diagrams show clearly the much greater growth requirements of $\mathrm{N}$ and $\mathrm{Si}$ than of $\mathrm{P}$. The carbon diagram is discussed in Part II. 
the surface, yet nitrate and silicate were used up at an enormous speed. Here phosphate seems to have been rather misleading. Subsequently until April 22nd all three salts were utilised in a fairly proportionate manner. All three show the spring outburst to be easing up by May 18th.

The early summer was a period of relative stagnation. The enormous increase in silicate at the bottom in June-August is not fully brought out owing to its peculiar distribution in the water. September provided some strange inconsistencies owing to the effect of "random " regeneration. Between August 26th and September 8th there was a short period of intense phosphate regeneration, yet nitrate showed a quite intense period of consumption. In the following fortnight the noteworthy feature was silicate consumption which went hand in hand with comparatively trivial net consumption of phosphate and with regeneration of nitrate. From October onwards the rate of return of nitrate grew steadily which seems very significant in light of its position at the end of the nitrogen return cycle and of its behaviour at the beginning of the year. Neither phosphate nor silicate showed any such regularity although downgrade processes definitely held the upper hand.

Comparison of the Magnitude and Date of Occurrence of the Winter Maxima for Phosphate, Silicate, and Nitrate.

The maximum values reached for each of the three salts varies considerably from year to year (Table VII).

\section{TABLE VII.}

Maximum values for $\mathrm{SiO}_{2}, \mathrm{P}_{2} \mathrm{O}_{5}$, and Nitrate (as Nitrogen and including Nitrite) Reached at Station E1 in Different Winters WITH DATES OF OBSERVATION.

Each as mg. per $\mathrm{m}^{3}$; average content of water column.

\begin{tabular}{|c|c|c|c|c|c|c|}
\hline & $\mathrm{Si}$ & & & D & Nitra & $-\mathrm{N}$ \\
\hline & Max. & Date. & Max. & Date. & Max. & Date. \\
\hline $1923-24$ & 288 & $15 / 2$ & 37 & $2 / 1$ & - & - \\
\hline $1924-25$ & $\geqq 345$ & $17 / 2$ & 32 & $9 / 12$ & - & - \\
\hline $1925-26$ & 250 & $3 / 2$ & 40 & $12 / 1$ & $71 \cdot 5$ & $10 / 4$ \\
\hline $1926-27$ & 375 & $15 / 2$ & 30 & $13 / 12$ & 88 & $24 / 11$ \\
\hline $1927-28$ & 350 & $4 / 11$ & $34 \cdot 7$ & $31 / 1$ & - & - \\
\hline $1928-29$ & 240 & $4 / 3$ & 31 & $2 / 1$ & - & - \\
\hline $1930-31$ & $\begin{array}{c}210 \\
\text { (twice) }\end{array}$ & $\left\{\begin{array}{l}13 / 1 \\
19 / 2\end{array}\right.$ & $29 \cdot 1$ & $4 / 12$ & $\begin{array}{c}98 \cdot 5 \\
\text { (twice) }\end{array}$ & $\left\{\begin{array}{l}4 / 12 \\
23 / 3\end{array}\right.$ \\
\hline $\begin{array}{l}\mathrm{n} \text { maximum } \\
\text { of winters }\end{array}$ & 294 & $(7 / 2)$ & $33 \cdot 4$ & $(27 / 12)$ & 86 & - \\
\hline Ivestigated & 7 & & 7 & & 3 & \\
\hline
\end{tabular}


Why the silicate winter maximum should vary so much more from winter to winter than phosphate or nitrate is not at all clear. A large positive deviation for silicate may coincide with an equally large negative one for phosphate or vice versa. There is here manifestly a factor fraught with possibilities as to the suitability of the sea to particular planktonic species in any particular season. A season with high phosphate and low silicate maxima such as 1925-26 would seem to favour those species of plankton which require little silica.

The approximate date when the silicate winter maximum was reached in the English Channel is seen to be about a month later than for phosphate-February 7th compared with December 27th. The winter of 1931-32 cannot be included since observations do not extend beyond January 28th, when the highest values, viz. $235 \mathrm{mg}$. $\mathrm{SiO}_{2}, 24 \cdot 7 \mathrm{mg}$. $\mathrm{P}_{2} \mathrm{O}_{5}$ and $115 \mathrm{mg}$. nitrate-nitrogen were found. These may have been exceeded subsequently.

In Table VIII the maxima found during the period, August, 1930, to January, 1932, for the five nutrient salts are given.

\section{TABLE VIII.}

Maxima for five Nutrient Salts and Time when reached. IN EACH CASE MG./ $\mathrm{M}^{3}$.

\begin{tabular}{|c|c|c|c|c|c|}
\hline Period investigated & $\begin{array}{c}\mathrm{P}_{2} \mathrm{O}_{5} \\
\text { Aug. ' } 30- \\
\text { Jan. '32. }\end{array}$ & $\begin{array}{c}\mathrm{SiO}_{2} \\
\text { Aug. '30- } \\
\text { Jan. '32. }\end{array}$ & $\begin{array}{c}\mathrm{NO}_{3}{ }^{\prime}-\mathrm{N} \\
\text { Nov. '30- } \\
\text { Jan. '32. }\end{array}$ & $\begin{array}{c}\mathrm{NO}_{2}{ }^{\prime}-\mathrm{N} \\
\text { Nov. '30- } \\
\text { Jan. '32. }\end{array}$ & $\begin{array}{c}\mathrm{NH}_{3}-\mathrm{N} \\
\text { Nov. '’30- } \\
\text { Nov. '31. }\end{array}$ \\
\hline \\
\hline L4 & $>30^{*}$ & 320 & 118 & $11 \cdot 5$ & $>40$ \\
\hline \multirow{3}{*}{ E1 } & $\begin{array}{r}11 / 11 / 30 \\
13 / 1 / 31\end{array}$ & $19 / 2 / 31$ & $4 / 12 / 30$ & $11 / 11 / 30$ & $\begin{array}{l}11 / 11 / 30 \\
20 / 10 / 31\end{array}$ \\
\hline & $29 \cdot 1$ & 210 & $115 \ddagger$ & $12: 4$ & $40 \dagger$ \\
\hline & $4 / 12 / 30$ & $\begin{array}{l}13 / 1 / 31 \\
19 / 2 / 31\end{array}$ & $28 / 1 / 32$ & $20 / 10 / 31$ & $11 / 11 / 31$ \\
\hline
\end{tabular}

The maxima for the winter of 1931-32 may not have been reached when observations ceased.

\section{Apparent Efficiency of Utilisation of Phosphate and Nitrate.}

Examination of the available data for the English Channel has shown that bottom nitrate is liable to undergo much more severe and prolonged depletion during the summer than is bottom phosphate. This also applies to a lesser extent to the surface salts. The nitrate used up in the spring

* High values at surface which cannot be used for calculating average content of the water column.

$\dagger$ This value may be slightly high. $30 \mathrm{mg}$. represents the upper limit which tended to be reached at seaward stations on other occasions.

$\ddagger$ In 1930-31 maxima of $98 \cdot 5 \mathrm{mg}$. were reached on $4 / 12 / 30$ and $23 / 3 / 31$. 
outburst was not materially restored by regeneration in the following months owing to the long cycle of reactions required to break down nitrogen in dead organic matter to nitrate. The re-formation of inorganic phosphate being so much simpler enabled this salt to be made available for a second growth process much more quickly. These conclusions, it is true, apply more obviously to waters below the thermocline, but similar regeneration in the surface waters, if it does occur, is more likely to be obscured.

Once the spring outburst is complete, it would seem that nitrate is much more likely to prove a limiting factor hindering further growth than is phosphate and that a marked increase in phosphate at midsummer may not necessarily be followed by a second phytoplankton outbreak. Thus during this period of the year nitrate is likely to prove the more reliable guide to the subsequent economy of the sea.

\section{NITRITE.}

Buch $(1925,1928)$ has made a detailed spectrographic study of the effect of temperature, time and salinity on colour development with the GriessIlosvay reagent. Orr (1926) found that in the Clyde Sea area in June, 1925, nitrite-nitrogen rarely exceeded $10 \mathrm{mg}$. per cubic metre, and was occasionally less than $1 \mathrm{mg}$. He discussed five different ways in which the nitrite content of sea-water might be changed. Atkins (1930 (1)) examined the fluctuations in nitrite in the English Channel between August, 1928, and March, 1929, and found as much as $38.9 \mathrm{mg}$. below the thermocline in August.

On the whole during 1931 nitrite was distributed uniformly throughout the water column (Figs. 5 and 13). At E1 minima were found in January, May, and July, and on the last two occasions the surface appeared to be completely exhausted. A combination of circumstances on the cruise of July 10th (see Methods, p. 722) favoured a very delicate series of analyses. At surface Stations L3 to L6 inclusive and at E1, surface, 5 and 10 metres, nitrite was shown definitely to be less than $0.02 \mathrm{mg}$. nitrogen per cubic metre or less than one part in $50,000,000,000$ parts of sea-water. To the writer's knowledge this is the most complete exhaustion of a constituent of sea-water yet recorded and probably approaches the analytical limit that can be attained by purely chemical technique.

The small increase over the January null values which occurred in the spring may be attributed to oxidation of ammonia and a maximum was reached on April 7th. In the succeeding fortnight, when heavy inroads were made on the store of nitrate, nitrite suffered a marked fall which would agree with its utilisation as a source of nitrogen. During the height of the summer it remained very low. With the onset of late summer

NEW SERIES.-VOL. XVIII. No. 2. JANUARY, 1933. 
regeneration a marked increase set in, but no values comparable with the exceedingly high values found by Atkins in 1928 were determined.

The three profiles for August and September illustrate the desirability of making nitrite determinations at as close intervals as possible. If the profiles for August 26th and September 25th, showing similar vertical distributions, stood alone, they might be interpreted as showing a period of little change. Yet the intervening profile for September 8th shows a quite different, far from uniform distribution.

There is laboratory evidence (p. 712) that nitrite would not decrease by $4 \mathrm{mg}$. nitrogen per cubic metre at the surface in thirteen days unless some noteworthy influence were at work.

At Station L4 the conditions through the year were so different from those at E1 as to make it impossible to draw a general inference. In midwinter 1930-31 and on November 30th, 1931, the nitrite content at L4 was several times that at E1. On January 13th, 1931, 7.2 mg. nitrogen per cubic metre was present in the water column at L4, whereas at E1 below 25 metres nitrite was not even detectable (i.e., less than 0.05 mg.). Yet in the early autumn of 1931 the distribution was quite reversed. Further, at this season the waters at L6 and E2 show only quite a rough relation with those at E1. This topic is further discussed below.

Owing to tidal and other water movements, precisely the same body of water cannot be sampled at a working station on every cruise. It is evident that distribution of nitrite is an exceptionally localised phenomenon in the English Channel and the state of affiairs at one station may give not the slightest indication of what may be occurring only a few miles away.

\section{Correlation between Nitrite Distribution and Hydrodynamic Conditions.}

The effect of the thermocline on the distribution of nitrite may be seen by comparing Atkins' data (1930 (1) ) for the late summer and autumn of 1928 with those for the corresponding period of 1931 (Table IV). In 1928 values in excess of $30 \mathrm{mg}$. nitrogen per cubic metre were found only beneath the thermocline and during its existence. After the breakdown of the thermocline at the end of September uniformity was soon approached.

In 1931, in July, the thermocline played no part since the entire water column was depleted. The temperature profile for August was in marked contrast to that of August, 1928. The stormy weather of mid-August, 1931, had destroyed the thermocline and although a temperature gradient still existed mixing of the waters must have been very considerable. As 
a result the high values of 1928 were not reproduced. The comparatively low results for 1931 and the uneven distribution for September 8th agree with the idea that nitrite as it comes into the upper layers may be directly assimilated by plants, and thus never become so high as when it is locked up beneath the thermocline.

The similar falling off in November in both years is striking.

\section{The Behaviour of Nitrite in the English Channel, Barents Sea and Antarctic Waters.}

N. Verjbinskaya (1932), working in the Barents Sea, has found nitrite figures which show striking similarities with E1 in the English Channel. In the work in the Barents Sea a large number of stations have been sampled quarterly, whereas in the Channel one station, E1, has been worked at more frequent intervals. The inshore Channel Station, L4, does not admit of detailed comparison with either E1 or the Barents Sea owing to land influences.

In midwinter in 1929 and 1930 along the meridian $73^{\circ} 30^{\prime} \mathrm{E}$. from the Murmansk coast to the ice margin, and in January, 1931, at E1 in the Channel, nitrite was scarcely detectable.* In both cases nitrification was presumably at a standstill. Intense consumption of phosphate and nitrate occurred in early April at E1 and in June in the Barents Sea. On both occasions nitrite appeared in fair quantity (around $4 \mathrm{mg}$. per cubic metre). In the region of water of Atlantic origin, the nitrite content was higher and the distribution in the water column more even than in Aretic or coast waters. Subsequently at E1 with vanishing nitrate, nitrite became very low. In August in the Barents Sea nearly all the nitrite was confined within the 50-100-metre layer, where it sometimes reached $14 \mathrm{mg}$. per cubic metre. Hydrodynamical conditions were similar at $\mathrm{E} 1 \mathrm{in} 1928$ and nitrite then reached $38 \mathrm{mg}$. In both cases a thermocline (E1, 25 metres ; Barents Sea, around 40-50 metres) prevented the nitrite in the enriched layers getting up to the surface.

Data for the Antarctic regions have been obtained by the Discovery Investigations. In the surface waters there, 6 to $8 \mathrm{mg}$. of nitrite-nitrogen per cubic metre was found in the presence of $350-500 \mathrm{mg}$. of nitratenitrogen over a wide area in summer. In the sub-Antarctic water, $3.5-5.5 \mathrm{mg}$. of nitrite-nitrogen accompanies about $200 \mathrm{mg}$. of nitratenitrogen in the surface to 100 -metres layer. Thus nitrite has not yet been found anywhere in the Antarctic to reach values commonly reached in the Channel.

* T. Soot-Ryen (1932) has recently found in North Norwegian fjords minima around mid-winter and mid-summer and maxima in April and October. The distribution in waters of corresponding depth is very similar to that of El. 


\section{AMMONIA.}

The importance of ammonia in the sea both as an intermediate in the conversion of decaying organic matter to nitrate and as a possible direct source of nitrogen assisting the growth of phytoplankton is widely recognised. The earlier methods for its determination involving distillation with alkali are suspect owing to the possible liberation of free ammonia from proteid material (cf. Buch, 1923, 1928; Wattenberg, 1928). Hagen (1931) has recently claimed that his method of distillation with magnesia and subsequent microtitration with acid avoids this difficulty.

Buch and Witting (Buch, 1928), Ibañez (1929) and Wattenberg have evolved methods which enable ammonia in sea-water to be determined without prior distillation. Wattenberg's procedure (1928) has been used by the writer in this investigation and is discussed in more detail in the later section on Methods (p. 717). It is not ideal for determinations on the waters of the English Channel for the following reasons :-

Wattenberg claims an accuracy of 5-15 mg. nitrogen per cubic metre, and the lower limit has usually been attained by the writer. Nevertheless, since the waters of the open Channel commonly contain less than $30 \mathrm{mg}$., the percentage error of any one determination is at least $20 \%$ and may be as high as $100 \%$ or more on a determination of, say, $5 \mathrm{mg}$. Thus, highly significant variations in ammonia may fail to be detected or observed differences may not inspire sufficient confidence. This criticism, if it is a criticism, applies not only to Wattenberg's method, but probably with equal force to any method, such as that of Buch and Witting, that makes use of the Nessler reagent. This reagent seems to be somewhat capricious, gives a yellow colour less suitable than a red or a blue for colorimetric comparison, shows large deviations from Beer's Law at such low concentrations of ammonia and is not quite sufficiently sensitive for its task as this presents itself in the English Channel. Unfortunately it is the only colorimetric reagent that even approaches the required sensitivity to ammonia. Also with methylamine it appears to give a colour about one-tenth as intense as that given by an equivalent amount of ammonia.

\section{Seasonal Changes in Ammonia.}

All the winter profiles for E1 (Fig. 6) and E2 (Fig. 7) are of similar form showing ammonia highest at the surface, least at 25-50 metres, with the bottom results lying in between. This accords with ammonia formation being mainly a surface phenomenon with lesser activity at the bottom. Nitrite, presumably formed from ammonia, shows a similar trend although the differences are not very marked (Fig. 5). Wattenberg has already established that ammonia formation in the East Greenland 
Sea is mainly a surface phenomenon. The data for L4 also show the ammonia content of the surface in winter to exceed that of the bottom.

In the spring ammonia showed a general tendency to decrease in the surface layers leading to more uniform distribution throughout the water column. Two reasons may be adduced for this. Firstly, the stock of organic material left over from the preceding year and forming the source of the ammonia would be expected to be less, and secondly, there is evidence (see p. 713) that ammonia may be directly utilised by the spring

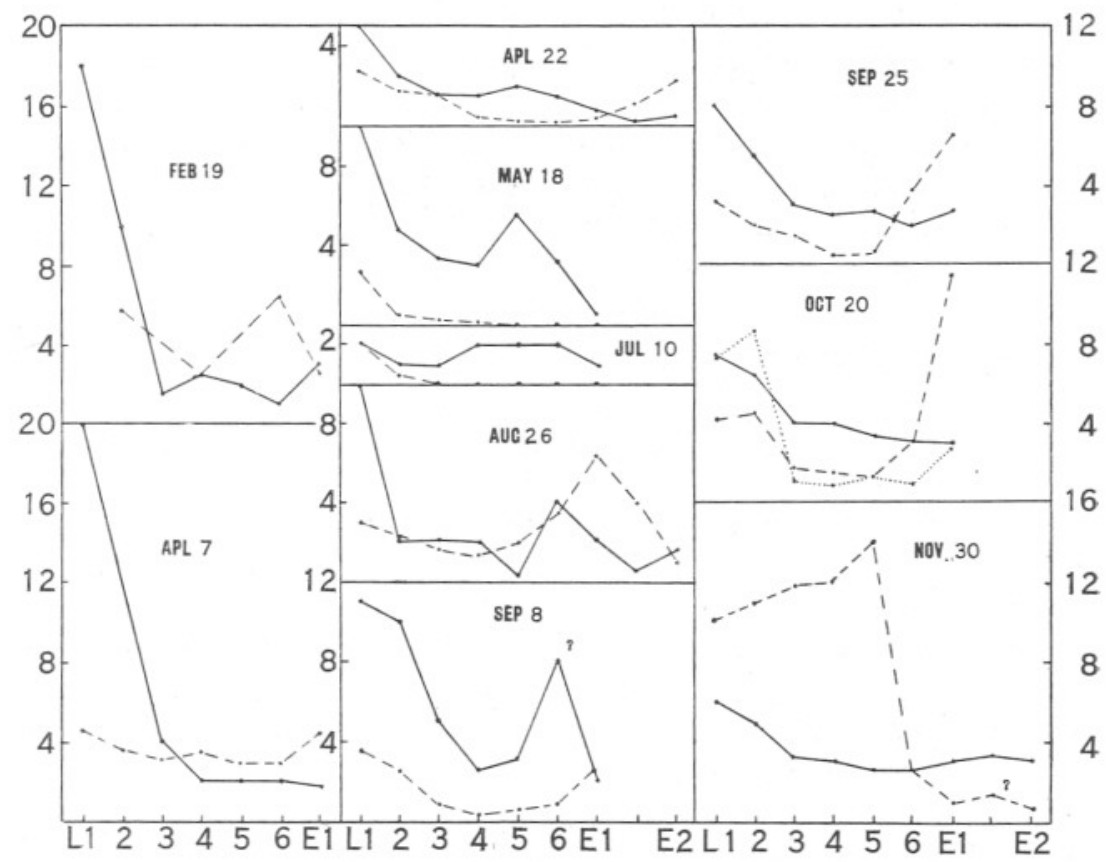

FIG. 15.-Relation between ammonia (full line) and nitrite (pecked line) content of surface water as the shore is approached, 1931. The scale for ammonia is ten times that shown for nitrite $\left(\mathrm{mg}\right.$. N per $\left.\mathrm{m}^{3}\right)$. Nitrate data are available for October 20 th (dotted line) and are shown on same scale as for ammonia. Distances between stations are not shown to scale. They are in nautical miles :$\mathrm{E} 2$

L1-2-L2 (Breakwater)-3-L3-3-L4-4-L5 (Eddystone)-5-L6-5-E1-17-Midway-17-

plankton outburst which would especially affect the surface and deplete the excess found in winter.

During the summer and autumn a general trend upwards can be traced, although ammonia never exceeded $30 \mathrm{mg}$. at the more seaward Stations L6 (not graphed), E1, and E2. In general $30 \mathrm{mg}$. appears to be the upper limit in the open Channel and higher figures such as some of those at L4 may be attributed to land or urban drainage. 
On the cruise of February 4th-5th determinations of the order of $200 \mathrm{mg}$. nitrogen per cubic metre were made on the deeper water from Station E3, 7 miles north-west of Ushant. Further data are not available for this Station where the complex water movements make a certain explanation difficult.

That land drainage may be of great importance is shown by the surface data from the $\mathrm{L}$ stations (Fig. 15). On most occasions the effect of land drainage was not apparent beyond L3, three miles outside the Breakwater. The ammonia content of the water in Plymouth Sound bears some relation to the state of the tide (Table IX). When, as on September 8th, ammonia was high on the first of the flood, the salinity was comparatively low, showing return of much water from the preceding ebb. The figures show the influerice on a tidal Sound of a fair-sized river and of the sewage of a large town which is discharged only on the ebb, as well as the rapidity with which ammonia, like phosphate and nitrate, is dissipated on mixing with the open sea.

TABLE IX.

Comparison of Surface Ammonia in Plymouth Sound and in the Open Channel, 1931.

(L1, Mallard Buoy ; L2, Breakwater ; E1, Open Channel.) Ammonia as mg. Nitrogen per eubic metre.

$\begin{array}{lccccccccccc}\text { Date } & 19 / 2 & 23 / 3 & 7 / 4 & 22 / 4 & 18 / 5 & 10 / 7 & 26 / 8 & 8 / 9 & 25 / 9 & 20 / 10 & 30 / 11 \\ \text { L1 } & 180 & 150 & \text { cal00 } & 50 & 100 & 20 & 100 & 110 & 80 & 75 & \text { ca60 } \\ \text { L2 } & 100 & \text { cal20 } & - & 25 & 48 & 10 & 20 & 100 & 55 & 65 & 50 \\ \text { E1 } & 30 & 5 & 17 & 7 & 5 & 10 & 20 & 20 & 27 & 30 & 30 \\ \text { State of Tide } & & & & & & & & & & & \\ \text { Hours Flood } & 1 \frac{1}{2} & 1 \frac{1}{2} & 1 & 5 & 2 \frac{3}{4} & 1 \frac{1}{2} & 2 & 2 & 2 & 1 \frac{1}{2} & 1 \frac{1}{2} \\ \quad \text { or Ebb } & \text { E. } & \text { E. } & \text { E. } & \text { F. } & \text { E. } & \text { F. } & \text { E. } & \text { F. } & \text { E. } & \text { F. } & \text { E. } \\ \text { Salinity, Ll } & 31.97 & 33.08 & 32.57 & 34 \cdot 58 & 33 \cdot 42 & 32 \cdot 76 & 31 \cdot 23 & 30 \cdot 72 & 33.67 & 33.48 & 29 \cdot 45\end{array}$

\section{THE INTERCONVERSION OF AMMONIA, NITRITE, AND NITRATE.}

The store of nitrate in the water is probably replenished through some such bacterial or chemical chain of reactions as the following :-

Dead proteid matter $\longrightarrow$ polypeptides $\longrightarrow$ aminoacids $\longrightarrow$ ammonia $\longrightarrow$ nitrite $\longrightarrow$ nitrate.

To obtain information as to the last two stages, a series of 44 experiments was made on water samples collected in the Sound (L1) at high and at low water and also at E1 at different depths. To certain of these known amounts of ammonia and of nitrite were added and determinations of ammonia, nitrite and nitrate were made after 10-13 days. Some samples were also preserved with mercuric chloride. In all cases the changes in nitrite were small, little more than the experimental error. The organic 
matter present in the L1 low-water sample had no effect on nitrite. Nitrate in the E1 bottom samples, including one preserved with mercuric chloride, decreased for a reason which is not clear. There was no correlation between the changes in ammonia and in the two oxy-acids, nor between the distribution of nitrite and the state of the tide at L1. The investigation of the oxidation of ammonia requires a longer period than ten days.

Examination of Fig. 13 which shows the changes in the average contents of ammonia, nitrite, and nitrate in the water columns at L4 and E1 brings out some interesting correlations. At E1 from January onwards the increase in ammonia seems to have been followed by increasing nitrite and nitrate. Indeed, the fact that nitrate went on increasing in March when phosphate and silicate were being depleted by photosynthesis is in excellent agreement with these prior-related increases in nitrite and ammonia.

During the period in mid-April when the salts definitely known to be of nutritional value were suffering rapid depletion, nitrite and ammonia did the same. This favours the view that both may be used as immediate sources of nitrogen for plant life, at any rate when nitrate is nearing exhaustion. Although ammonia increased during the midsummer period, nitrite remained very low, probably on account of the simultaneous dearth of nitrate. During this period scarcity of phosphate was exerting a second independent control over the growth of diatoms so that it is quite likely that the reserves of ammonia were never called upon.

During the early autumn a further increase in ammonia to about $25 \mathrm{mg}$. nitrogen per cubic metre took place and was followed by nitrite formation. Still later nitrate also began to increase towards its winter maximum. However, there was a short period at the beginning of September when both nitrate and nitrite showed marked falls whilst ammonia was lower in the surface than in the deeper waters. This is in accord with consumption of all three by plankton.

Decisive laboratory experiments on marine phytoplankton to establish the suitability for growth of different nutrient salts require bacteria-free pure cultures. Schreiber (1927), with such a culture of the unicellular alga, Carteria, has shown conclusively that nitrite and ammonia are utilised as readily as nitrate.

Further pure cultures of centric diatoms, such as Biddulphia mobiliensis and Melosira, showed luxuriant growths with each of the above sources of nitrogen, but since they were not free from bacteria the results were less conclusive. Harvey (unpublished work) has also found that cultures of Nitzschia were able to assimilate ammonia in the Laboratory.

Braarud and Föyn (1931) have carried out a series of experiments, similar to Schreiber's, using absolutely pure cultures of Chlamydomonas, 
with 5 to $10 \mathrm{mg}$. per 100 c.c. of the appropriate nitrogen compound added. They found that it, like Carteria, was able to utilise ammonia even more efficiently than nitrate, but glycine although usable was by no means as effective as for Carteria. Alanine, asparagine (optical rotation not stated), and urea gave yields of the alga roughly comparable with that given by glycine.

Although these algæ might still prefer nitrate if they could get it, there can be no doubt that they are well able to utilise nitrite, ammonia, and even aminoacids. This conclusion is probably of general application so that the evidence for their utilisation in the English Channel receives strong support.

From these results in 1931 the following conclusions may be tentatively deduced :-

(1) Ammonification of proteid matter is primarily a surface phenomenon which receives some assistance from the bottom waters. It is most evident in winter, but in spring and summer it may be masked by simultaneous direct utilisation by the plankton.

(2) An increase in ammonia would seem to be followed by an increase in nitrite and later in nitrate, although the necessary interval of time cannot be stated with any degree of certainty. It is not more than one or two months. The process of nitrification appears to go on throughout the water column and not merely at the bottom.

(3) Both ammonia and nitrite seem to be utilisable by the phytoplankton in the spring and autumn when nitrate is low.

(4) As the shore is approached, ammonia increases, but there is no. correlated change in nitrite.

\section{THE GRAM-ATOM AS A COMMON RATIONAL UNIT FOR NUTRIENT SALTS.}

Phosphate and silicate have usually been given in terms of mg. $\mathrm{P}_{2} \mathrm{O}_{5}$ and $\mathrm{mg}$. $\mathrm{SiO}_{2}$, and nitrogen compounds in terms of $\mathrm{mg}$. $\mathrm{N}$, the unit of volume being the cubic metre. It has also been suggested that phosphate and silicate be given as mg. $\mathrm{P}$ and $\mathrm{mg}$. Si or as $\mathrm{mg}$. $\mathrm{PO}_{4}{ }^{\prime \prime \prime}$ or $\mathrm{mg}$. $\mathrm{SiO}_{3}{ }^{\prime \prime}$. Any advantages these changes might bring seem scarcely sufficient to warrant departure from well-established custom.

In the earlier work on the minor constituents of sea-water the method of presentation of results was of no great importance, but now that more and more work is concerned with comparison between the different chemical factors a more rational method seems to be called for. The need promises to become still more marked.

In the same way that the concept of the chemical equivalent simplifies 
volumetric analysis, a similar concept would probably simplify oceanographical chemistry. But, since the unit with which plants build is the atom, the gram-atom of phosphorus, silicon or nitrogen seems preferable to the gram-equivalent. In practice a sub-multiple such as the milligramatom $\left(10^{-3}\right.$ gram-atom $)$ or $\frac{1}{10} \sigma$ milligram-atom $\left(10^{-5}\right.$ gram-atom $)$ per cubic metre would need to be used.

In studying the seasonal plankton outbursts, comparison of changes in phosphorus, silicon or nitrogen in terms of the milligram-atom would give a direct measure of the elements in terms of the common significant unit with which the plants themselves are concerned. It follows that the atomic ratios $\mathrm{P}: \mathrm{Si}: \mathrm{N}: \mathrm{N}: \mathrm{N}$ will be numerically identical with the molecular ratios $\mathrm{H}_{3} \mathrm{PO}_{4}: \mathrm{H}_{2} \mathrm{SiO}_{3}: \mathrm{HNO}_{3}: \mathrm{HNO}_{2}: \mathrm{NH}_{3}$ or the ionic ratios $\mathrm{PO}_{4}{ }^{\prime \prime \prime}: \mathrm{SiO}_{2}{ }^{\prime \prime}: \mathrm{NO}_{3}{ }^{\prime}: \mathrm{NO}_{2}{ }^{\prime}: \mathrm{NH}_{4}{ }^{\circ}$, a point of definite practical importance. A similar concept might also prove useful for other constituents of sea-water such as calcium and iron. For oxygen and carbon dioxide the present method of presentation in c.c. per litre at N.T.P. is already based on a similar idea since, according to Avogadro's hypothesis, equal volumes of different gases at N.T.P. contain the same number of molecules.

It is felt that such a radical change in the method of presenting results, before being put into service, requires the concurrence of the majority of oceanographical chemists, as uniformity in practice above all else is desirable. In consequence the conventional method has been used in this paper, with the exception of Section VI.

\section{METHODS.}

\section{Рhosphate.}

The cœruleomolybdic method of Denigès as adapted by Atkins for determinations in sea-water (1923 (1) et seq.) has been used. The solution of stannous chloride used for reduction requires to be strongly acid. The blank correction for the blue colour inherent in sea-water and for impurities in the reagents (usually nil) has been applied as described by Atkins (1930, p. 848).

A practice has been made in all work with Hehner tubes not to run down the standard column below 40 c.c. (compared with 100 c.c. of sample) as the differing fields of view make an accurate colour match difficult of achievement. Since in finding the blank correction this condition is infringed with any standard stronger than $10 \mathrm{mg} . \mathrm{P}_{2} \mathrm{O}_{5}$ per cubic metre, such a standard is usually prepared. But when two standards of different strengths are available, an alternative method of calculating the blank correction, $k$, may be used. 
Suppose that 61.5 c.c. of a standard containing $20 \mathrm{mg}$. of $\mathrm{P}_{2} \mathrm{O}_{5}$ per $\mathrm{m}^{3}$. matches 100 c.c. of another standard containing only $10 \mathrm{mg}$.

Then equating the two sides to the colour match :-

$$
\begin{aligned}
10+k & =\frac{61 \cdot 5}{100} \cdot(20+k) \\
38 \cdot 5 k & =230 \\
k & =6 \cdot 1
\end{aligned}
$$

Standards have always been so compared not only for this purpose but as a check on one another. The lower limit of sensitivity of the method has been found around 1 or $0.5 \mathrm{mg}$. $\mathrm{P}_{2} \mathrm{O}_{5}$ per $\mathrm{m}^{3}$. No correction has been made for salt error.

Denigès (1929) has recently stated that the blue compounds derived from the two "phosphoroïdes : P ou As " upon which his method is based have been isolated as rhombic crystals, analysing in accordance with

$$
\left[4\left(\mathrm{MoO}_{3} \cdot \mathrm{MoO}_{2}\right)\right]_{2} \phi \mathrm{O}_{4} \mathrm{H}_{3}, 4 \mathrm{H}_{2} \mathrm{O}
$$

where $\phi$ represents the phosphoroïde. He has proposed a structural formula.

The high molecular weights of these compounds (1578 for that from phosphorus) are about 50 and 22 times greater than the atomic weights of $\mathrm{P}$ and As, thus facilitating the determination of traces. Denigès also discusses the solubility of the molybdenum blues in organic solvents (cf. also Wu, 1920).

\section{Silicate.}

The method of Diénert and Wandenbulcke, introduced into sea-water analysis by Atkins has been used. The colour produced by neutral ammonium molybdate in presence of dilute sulphuric acid is compared with that of standard picric acid solutions. The results are correct according to King and Lucas's standard (Atkins, 1930, p. 848, and slip in Journ. Mar. Biol. Assoc., Vol. XVII, No. 3).

Results quoted from earlier papers have been corrected to this standard by multiplying results in the above reference by $1 \cdot 10$ and in the other papers by $1 \cdot 44$.

Hehner tubes were not considered too satisfactory for the comparison, since inshore waters and certain E1 plankton rich surface waters were found to possess an inherent marked yellow colour. Instead, the apparatus described and illustrated by Harvey (1928 (2) ) was used. The horizontal tubes were $60 \mathrm{~cm}$. long and $1.6 \mathrm{~cm}$. wide with a capacity of only 120 c.c. These have side-arms through which they can be filled. The presence of turbidity is countered by the presence of a similar sample of sea-water in the twin tube. No blank correction is required, but since acid tends to precipitate the plankton and sediment 
in the sample, the same amount of sulphuric acid was added to the contents of the twin tube, and both were allowed to settle for five minutes before effecting comparison. A distinct brown deposit formed with very turbid water, in which case an error of $50-100 \mathrm{mg}$. $\mathrm{SiO}_{2}$ per $\mathrm{m}^{3}$. may be introduced if the settling be omitted. In some cases, indeed, it may be necessary to wait until a lapse of a further 5-10 minutes causes no change in the reading.

If the wedges are calibrated in millimetres width, calculation of results is very simple.

Let the wedge reading at colour match be $y \mathrm{~mm}$.

And let the picric acid colour standard be equivalent to a solution of silicate containing $c \mathrm{mg}$. $\mathrm{SiO}_{2}$ per $\mathrm{m}^{3}$.

Then since the tubes are $600 \mathrm{~mm}$. long the strength of the unknown solution of sea-water, $x$, is given by :-

$$
x=\frac{c . y}{600}
$$

By this means the smallest amount of silicate which can be determined with certainty is about $20 \mathrm{mg}$. $\mathrm{SiO}_{2}$ per $\mathrm{m}^{3}$. At about $200 \mathrm{mg}$. per $\mathrm{m}^{3}$. the results in general are accurate to within about $\pm 10 \mathrm{mg}$. The mean of 3-4 readings has been taken. Since a "daylight" lamp was found unsuitable, comparison was always effected by bright diffused daylight.

Waxed bottles have been found essential for storing samples for silicate determination (cf. Atkins, 1928). Several discordant results have been obtained with samples taken from the standard dark-green sample bottles in use at Plymouth.

Thayer (1930) has recently examined the molybdimetric methods for silicate and phosphate with respect to cross-interference and interference by iron. Their results appear to support Atkins that no trouble should be experienced at the concentration in which these substances are usually present in sea-water, but the paper may be of interest to investigators who have to study waters much richer than those on the European continental shelf.

\section{Ammonia.}

The method of direct Nesslerisation of sea-water in presence of sodium hydroxide and Rochelle salt introduced by Wattenberg (1928) has been used. Since the samples have to be stored in the laboratory for a week or more before analysis, four drops of saturated mercuric chloride solution have been added to each sample (170 c.c.) on collection. This has no effect on the determination and has been shown to keep the water unchanged up to at least four months.

The method used is essentially as described by Wattenberg although one or two small changes in technique have been made. Reagents, 
other than Nessler, are made up the night before they are required for use in order to avoid contamination. The Nessler reagent has been made up exactly as described by Wattenberg except that it is two-thirds the strength and 1.5 c.c. instead of 2 c.c. is used for each analysis. It is believed that a slight increase in sensitivity is thus achieved. Further decrease in the amount of reagent seems to lead to inaccurate colour development with the stronger solutions of ammonia.

When the method was first examined it proved difficult to get clear solutions. Indeed, most of the troubles since recorded by Braarud and Klem (1931) were experienced. One or two small changes in technique were made and since then cloudiness has not interfered. It is true that the solutions sometimes begin to cloud after an hour, but within this time the comparisons may be easily effected. A detailed account of the routine adopted here may be useful.

One 350 c.c. conical flask or conical beaker and one 250 c.c. or 350 c.c. open beaker are required for each sample or standard. The series of labelled flasks is placed along the bench, each with a beaker and sample bottle behind. The appropriate amount of a standard ammonia solution is then added to each standard flask followed by 100 c.c. of the standard sea-water to which a small but definite excess of ammonia-free hydrochloric acid (e.g. constant boiling acid) has been added. If the sea-water after boiling with alkali has been brought only to neutrality, turbidity may ensue due to colloidal calcium and magnesium compounds remaining undissolved. Into each sample flask 100 c.c. of the sample is measured with a cylinder. The next operation is to add 10 c.c. of $20 \%$ boiled out caustic soda to each open beaker.

Instead of adding all the Rochelle salt (5 c.c.) to the sea-water, about 0.5 to 1 c.c. is added to the caustic soda and the remainder to the sea-water. This appears to give a test solution which remains clear longer. Each flask of sea-water is then poured into the corresponding beaker of caustic soda at first slowly and then rapidly while imparting a rapid swirling motion to the contents, which are finally poured quickly back into the flask. As a further check against development of turbidity the addition of Rochelle salt and mixing may be made in groups of six at a time.

The addition of Nessler reagent is made from a quick delivery burette so as to reduce the time interval between the first addition and the last to a minimum. The solutions are best transferred at once to the comparator although 15-20 minutes must be allowed for the development of colour. Attention to detail has been found essential to success with this method, and the work must be carried through with the greatest speed compatible with accuracy.

The early type of comparison tube evolved by Harvey and described by Wattenberg (1928) was first used. Optically it is excellent, but it was 
found dirty to work with since alkaline mercurial solution was often spilt in fitting the lens. The apparatus at present in use avoids this completely. The total length of the tube is $38 \mathrm{~cm}$. and width $1.7 \mathrm{~cm}$., except that it has a parallel-sided bell-top, $3 \cdot 2 \mathrm{~cm}$. wide. Its length is $3 \mathrm{~cm}$. The bell-top is filled in each case to the same extent and avoids all spilling. The tube is viewed vertically through the centre of the bell where the meniscus is only very slightly concave. No lens is required.

The stand which holds thirteen tubes simultaneously consists of an open wooden box with a sliding front for use if required. Internal measurements : length, $58 \mathrm{~cm}$., height, $53 \mathrm{~cm}$., breadth, $8 \mathrm{~cm}$. The tubes are held vertically by spring clips screwed to a strengthening piece fixed across the back of the box. The bottom of each tube is supported on a clear glass plate, $58 \times 6.4 \mathrm{~cm}$. carried on rests at the back and sides and $18 \mathrm{~cm}$. above the bottom of the box. This plate bears no appreciable weight, serving mainly to adjust all the tubes to the same height. Light from a north window is reflected up through the tubes by a matt opal-glass plate, $58 \times 10.5 \mathrm{~cm}$., held at a suitable angle in the bottom by a slat of wood. In this apparatus standards and samples may be quickly arranged in sequence.

The following close series of standards was usually made up, viz. $0,0,5,10,10,15,20,20,25,30,40,60,80 \mathrm{mg}$. $\mathrm{N}$ per $\mathrm{m}^{3}$. By comparison of these together any untrustworthy standards may be at once rejected. Duplication of some of the standards is very desirable. Interpolation is dangerous. Also after April 22nd, 1931, the sets of duplicate analyses were always made independently with different sets of standards.

It is possible to use Hehner tubes with advantage for comparing samples containing more than $40-50 \mathrm{mg}$. $\mathrm{N}$ per $\mathrm{m}^{3}$. Since Beer's Law is quite invalid a special calibration curve must be constructed by comparing lower with higher standards. The departure from Beer's Law appears to increase with age of the Nessler reagent so that a fresh curve must be constructed on each occasion.

Determinations of less than $100 \mathrm{mg}$. $\mathrm{N}$ per $\mathrm{m}^{3}$. are thought to be accurate to about $\pm 5 \mathrm{mg}$. A series containing $0,3,5,7$, and $10 \mathrm{mg}$. $\mathrm{N}$ per $\mathrm{m}^{3}$. can be placed in sequence with a fair degree of certainty, but agreement between independent duplicate determinations is not always quite so good.

\section{Possible Interference by Organic Nitrogen Compounds.}

It seemed possible that amino-acids and alkylamines which may be present in sea-water might be able to form a yellow complex with the Nessler reagent sufficient to upset ammonia determinations. Known amounts of glycine, aspartic acid, methylamine hydrochloride, dimethylamine hydrochloride, and ethylamine hydrochloride were therefore 
added to standard sea-water and compared with ammonia standards at the same time as the samples from the cruise of October 20th. Only the glycine was a B.D.H. analytical reagent. The other amines were ordinary B.D.H. products taken direct from the laboratory stock. The dimethylamine hydrochloride was very wet. The results are given in Table X.

\section{TABLE $\mathrm{X}$.}

Effect of Amino-acids and Alkylamines in Sea-water on Nessler Reagent.

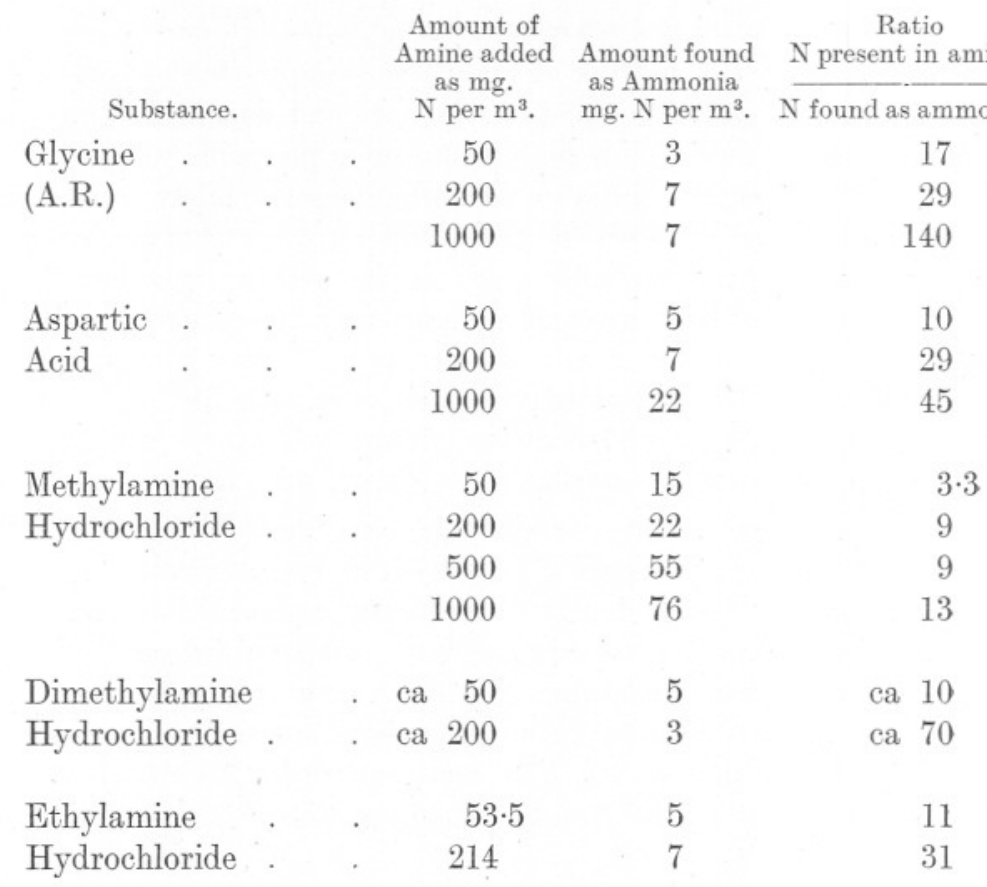

Unless present in very large amounts, the effect of glycine and dimethylamine appears to be unimportant, but aspartic acid and ethylamine both impart a slight yellow colour to the reagent. Methylamine gave one-tenth of the colour given by an equivalent amount of ammonia. The smaller observed influences may have been due to ammonia present in the materials. In the case of methylamine this explanation would involve the presence of $10 \%$ of ammonium chloride as impurity which seems highly unlikely. On one occasion trimethylamine coming from a barrel of herrings on the floor below was found to upset ammonia determination. Thus, excepting methylamines, it seems safe to ignore the influence of amino-acids and alkylamines on the Nessler reagent. 


\section{Nitrate.}

The determination of nitrate is described elsewhere (Harvey, 1928 (2) ; Cooper, 1932).

\section{Nitrite.}

The standard Griess-Ilosvay reagent (Orr, 1926; Wattenberg, 1931) has been used. The distilled water used for making up reagents and standards has been redistilled from caustic soda or baryta immediately before use into a Winchester bottle. This was fitted with a soda lime tube to stop ingress of nitrous gases always present in a laboratory in which gas burners are in use. No burners were allowed to be used when colour comparison was being made.

A special routine was developed to avoid change in nitrite whilst bringing the samples to the Laboratory for analysis. A box of 36 standard sampling bottles has been kept solely for nitrite samples. The series of standards required was prepared in these bottles on the morning of the cruise. About 100-120 c.c. of water was then collected in the remaining bottles at each station as required. The two Griess-Ilosvay reagents were mixed on the ship and 4 c.c. of the mixed reagent measured in a cylinder was added at once to each sample and standard. The colour was allowed to develop overnight and comparison made next morning. The idea that nitrite in the sea is very fugitive has since been found to be open to doubt but since the method is very expeditious it has been retained. Colour development in the actual sample bottle has a further advantage in that transference to laboratory glassware is avoided, thus eliminating an ever-present risk of contamination. Little change occurs in the colour of the dyestuff up to 4 or 5 days in darkness after which it begins to turn brown, thus vitiating results obtained. After cruises to E2, satisfactory comparison has been effected when addition of reagent had been made 40 hours earlier.

The following series of standards, each in duplicate, has usually been prepared : 0, 1, 2, 5, 10, $25 \mathrm{mg}$. $\mathrm{N}$ per $\mathrm{m}^{3}$. Preliminary comparison of each pair with one another and with the next higher standard enables any untrustworthy standard to be discarded and gives an alternative means of calculating the blank correction. The reagent itself has always been found free from detectable colour, but since, in contrast to phosphate, the correction factor applies to nitrite present in the distilled water used for making the standards and not to any pink colour inherent in sea-water, it is calculated differently.

Thus, suppose that 20 c.c. of a nitrite standard containing $1 \mathrm{mg}$. N per $\mathrm{m}^{3}$.+reagent matches 100 c.c. of redistilled water+reagent.

Let the amount of nitrite present as impurity in 100 c.c. of redistilled water, and consequently in the standard also, be $x \mathrm{mg}$. per $\mathrm{m}^{3}$.

Then

$$
x=\frac{20}{100}(1+x)=0 \cdot 25
$$


Then every standard will also contain $0 \cdot 25 \mathrm{mg}$. $\mathrm{N}$ per $\mathrm{m}^{3}$., more than its nominal content.

If $y$ c.c. of a nominal $2 \mathrm{mg}$. standard matches 100 c.c. of sea-water sample, then its nitrite content, $c$, will be given by

$$
c=\frac{y}{100}(2+0 \cdot 25)
$$

$0 \cdot 3 \mathrm{mg}$. per $\mathrm{m}^{3}$. has been regarded as the maximum permissible nitrite content of the distilled water, usually it was less than $0.1 \mathrm{mg}$. and it was often not detectable.

With about $5 \mathrm{mg}$. $\mathrm{N}$ per $\mathrm{m}^{3}$. present, the determinations are accurate to about $0 \cdot 1 \mathrm{mg}$. At the lower limit using distilled water completely free from nitrite, 0.02 and $0.04 \mathrm{mg}$. may be just distinguished under very favourable conditions. This degree of accuracy is not usually necessary nor has it been often attained owing to the presence of a positive blank correction. However, on July 10th, 1931, at the surface Stations, L3 to L6, at L4, 50 metres, and at $\mathrm{E} 1,0,5$, and 10 metres, nitrite was shown definitely to be less than $0.02 \mathrm{mg}$. $\mathrm{N}$ per $\mathrm{m}^{3}$., i.e. less than 1 part in $50,000,000,000$. The colour of the sea-water plus reagent was indistinguishable from distilled water with or without reagent.

In all cases where nitrite has proved undetectable, a drop of $0 \cdot 1 \%$ sodium nitrite has afterwards been added to the test sample to confirm the presence of the reagent added on the ship.

Germuth (1929) recommended the replacement of $\alpha$-naphthylamine by its dimethyl derivative. Amongst other advantages, it was claimed that the resulting dyestuff does not fade appreciably in 60 days in light. A sample (5 g.) of dimethyl- $\alpha$-naphthylamine obtained commercially was a dark brown liquid insufficient for purification by distillation and when made up in the same way as $\alpha$-naphthylamine gave a faintly pink solution. The tint developed with sulphanilic acid and nitrite was almost identical in intensity and quality of tint with the standard Griess-Ilosvay colour. Similar solutions when exposed to diffuse daylight for one week showed a similar amount of fading and discoloration. Dimethyl- $\alpha$-naphthylamine is much dearer and as obtained commercially was less pure than $\alpha$-naphthylamine over which for sea-water analysis it seems to have no advantage.

\section{Áverage Nutrient Salt Content of the Water Column.}

The total nutrient salt (e.g. phosphate) content of the water column is first found and then divided by the depth to give what is termed in this paper the average phosphate content of the water column.

For purposes of calculation and generally in the construction of depth 
profiles, adjacent points are joined by straight lines to give a discontinuous curve (Figs. 1-7). The distribution of nutrient salts in the sea is probably seldom accompanied by such a discontinuity. However, such profiles seem as legitimate as any of the possible smooth curves which might be fitted to the points.

The total nutrient salt may be found in several ways, e.g. with a planimeter or by counting squares, the method used by Atkins. In this paper it has been calculated directly from the data.

Suppose determinations are made at depths $y_{1}, y_{2}, y_{3} \ldots y_{n}$ metres apart and give nutrient salt contents $a, b, c \ldots n$ milligrams per cubic metre.

Then the total salt content between the surface and $y_{1}$ metres will be $\frac{a+b}{2} \cdot y_{1}$. Similarly for the other depths.

Then the total nutrient salt content of the whole water column,

$$
\Sigma \text { Nutrient Salt }=\frac{a+b}{2} \cdot y_{1}+\frac{b+c}{2} \cdot y_{2} \ldots+\frac{m+n}{2} \cdot y_{n} .
$$

This summation may be quickly made in practice since certain terms may often be taken together to give a convenient numerator, e.g. when $y_{1}=y_{2}$, then

$$
\frac{a+b}{2} \cdot y_{1}+\frac{b+c}{2} \cdot y_{2}=\frac{a+2 b+c}{4} \cdot 2 y_{1} .
$$

$2 y_{1}$ is often equal to 10 .

The summation equation may be transformed to give :-

$$
\Sigma \text { Nutrient Salt }=\frac{1}{2}\left[y_{1} a+\left(y_{1}+y_{2}\right) b+\left(y_{2}+y_{3}\right) c \ldots+y_{n} n\right] .
$$

If $D$ is the total depth in metres $=\left(y_{1}+y_{2}+y_{3} \ldots+y_{n}\right)$, then the average nutrient salt content is $\frac{\sum \text { Nutrient Salt }}{D}$.

\section{ACKNOWLEDGMENTS.}

The author has to thank Dr. E. J. Allen, Dr. W. R. G. Atkins and Mr. H. W. Harvey for their continued interest in the work described in this and the following paper and for a great deal of valuable criticism and advice. $\mathrm{He}$ is also indebted to Capt. V. Lord and the crew of the ss. Salpa for their assistance, so willingly given, in the work at sea. 


\section{SUMMARY.}

Determinations of phosphate, silicate, nitrate, nitrite and ammonia have been made at frequent intervals at two Stations, L4 and E1, in the English Channel off Plymouth between the autumn of 1930 and January, 1932. Determinations were also made quarterly at E2 in mid-Channel.

The year 1931 was an early one from the point of view of plankton production. The chemical data show that there was a small mid-winter outburst which gathered momentum during January and February. The main spring outburst started, however, early in March, carrying on fairly steadily until about the middle of May. The summer was characterised by exceptionally low phosphate and nitrate right through the water column due to very efficient utilisation in the spring and to the unusual hydrodynamical conditions. There was also a small autumn outburst.

The outburst at E2 in mid-Channel in 1931, as in several former years, began earlier than at E1, but by mid-April production at $\mathrm{E} 2$ had been far surpassed by that at E1, again in agreement with former years.

The date of the winter maximum has varied fairly regularly for different salts. That for silicate has been about a month later than that for phosphate and its magnitude has varied greatly from year to year. Nitrate in 1931 showed three maxima, one at mid-winter, one in March when the plankton outburst was well under way, and one in the late summer. Thus nitrate, whose formation is the last stage in the long nitrogen regeneration cycle, was unreliable as a criterion of plankton production in the early spring although it was valuable at other seasons.

In three seasons out of four silicate has shown a summer maximum about August due to re-solution at the bottom of siliceous matter, including the skeletons of diatoms dying off after the spring outburst. A minimum usually followed related with the autumn outburst.

Almost complete exhaustion of nitrite was found at E1 in January, May and July. Nitrite in the sea has been found to be fairly stable, although its distribution in the Channel is exceptionally localised. The amount seemed to be dependent on the amount of ammonia present a few weeks before. In the autumn the distribution of nitrite has been very dependent on hydrodynamical conditions.

The determination of ammonia in sea-water is discussed. Ammonia formation was mainly a surface phenomena which received some assistance from the bottom waters (at about 70 metres). In spite of vertical mixing this was most apparent in winter. The mechanism of the interconversion of ammonia, nitrite and nitrate and the utilisation of ammonia and nitrite by plants are discussed. 
The first two months of 1931 were sunny leading to an early diatom outburst, but the late spring and summer were unusually sunless and stormy, the effect of which on the utilisation and distribution of nutrient salts is clearly brought out.

\section{REFERENCES.}

Atkins, W. R. G. 1923 (1). The Phosphate Content of Fresh and Salt Waters in its Relationship to the growth of the Algal Plankton. J. Marine Biol. Assoc., N.S., Vol. 12, pp. 119-150.

Atkins, W. R. G. 1923 (2). The Silica Content of Some Natural Waters and of Culture Media. J. Marine Biol. Assoc., N.S., Vol. 13, pp. 151-159.

Atkins, W. R. G. 1925. Seasonal Changes in the Phosphate Content of Sea Water in relation to the Growth of the Algal Plankton during 1923 and 1924. J. Marine Biol. Assoc., N.S., Vol. 13, pp. 700-720.

Atkins, W. R. G. 1926 (1). Seasonal Changes in the Silica Content of Natural Waters in Relation to the Phytoplankton. J. Marine Biol. Assoc., N.S., Vol. 14, pp. 89-99.

Atrins, W. R. G. 1926 (2). The Phosphate Content of Sea-Water in relation to the Algal Plankton. Part III. J. Marine Biol. Assoc., N.S., Vol. 14, pp. 447-467.

Atkins, W. R. G., and Wilson, E. G. 1927. The Phosphorus and Arsenic Compounds of Sea-Water. J. Marine Biol. Assoc., N.S., Vol. 14, pp. 609-614.

Atrins, W. R. G. 1928. Seasonal Variations in the Phosphate and Silicate Content of Sea-Water during 1926 and 1927 in Relation to the Phytoplankton Crop. J. Marine Biol. Assoc., N.S., Vol. 15, pp. 191-205.

Aткıns, W. R. G. 1930 (1). Seasonal Changes in the Nitrite Content of Sea-Water. J. Marine Biol. Assoc., N.S., Vol. 16, pp. 515-518.

Atкins, W. R. G. 1930 (2). Seasonal Variations in the Phosphate and Silicate Content of Sea-water in Relation to the Phytoplankton Crop. Part V. November, 1927, to April, 1929, compared with Earlier Years from 1923. J. Marine Biol. Assoc., N.S., Vol. 16, pp. 821-852.

Atkins, W. R. G. 1932. Nitrate in Sea-water and its Estimation by means of Diphenylbenzidine. J. Marine Biol. Assoc., N.S., Vol. 18, pp. 167-192. 
Bachrach, E., and Lefèvre, M. 1928. Disparition de la carapace silicieuse chez les diatomées. Comptes rendus. Soc. biol., Vol. 98, pp. 1510-1511.

Bachrach, E., and Lefìvre, M. 1929. Contribution à l'étude du rôle de la silice chez les êtres vivants. Observations sur la biologie des diatomées. Journ. de Physiologie et de Pathologie générale, Vol. 27, pp. 241-249.

Braarud, T., and Föyn, B. 1931. Beiträge zur Kenntnis des Stoffwechsels im Meere. Avhandlinger Norske Videnskap-Akademi i Oslo. I. Matem.-Naturvid. Klasse, 1930, No. 14, pp. 1-24.

Brandt, K. 1916-20. Über den Stoffwechsel im Meere. Wiss. Meeresuntersuchungen, Kiel, Vol. 18, p. 339.

Brandt, K. 1927. Stickstoffverbindungen im Meere. Wiss. Meeresuntersuchungen, Kiel, Vol. 20, pp. 200-292.

Buch, K. 1923. Methodisches über die Bestimmung von Stickstoffverbindungen im Wasser. Merentutkimuslaitoksen Julkaisu Havsforkningsinstitutets Skrift No. 18, pp. 1-22.

BucH, K. 1928. Über die Bestimmung von Stickstoffverbindungen und Phosphaten im Meerwasser. Conseil Int. p. l'Exploration de la Mer. Rapports et Procès-verbaux, Vol. 53, pp. 36-52.

Cooper, L. H. N. 1932. The Reduced Strychnine Reagent for the Determination of Nitrate in the Sea. J. Marine Biol. Assoc., N.S., Vol. 18, pp. 161-166.

Denigès, G. 1929. La céruléo-molybdimétrie méthode de micro-dosage des ions phosphoriques et arséniques. Mikrochemie, Pregl-Festschrift, pp. 27-45.

Germuth, F. G. 1929. Dimethyl- $\alpha$-naphthylamine for Determination of Nitrite Ion. Ind. Eng. Chem., Analytical Edn., Vol. 1, p. 28. Brit. Chem. Abs., 1929, A, 414.

Gran, H. 1931. On the Conditions for the Production of Plankton in the Sea. Conseil Int. p. l'Exploration de la Mer. Rapports et Procès-verbaux, Vol. 75, pp. 36-46.

Hagen, S. K. 1931. Titrimetric Determination of Very Small Quantities of Ammonia with especial Reference to Sea and Fresh Water (in German). Zeits. f. anal. Chemie, Vol. 83, 164.

Harvey, H. W. 1923. Hydrographic Features of the Water in the Neighbourhood of Plymouth during the years 1921 and 1922. J. Marine Biol. Assoc., N.S., Vol. 13, p. 225. 
Harvey, H. W. 1926. Nitrate in the Sea. J. Marine Biol. Assoc., N.S., Vol. 14, p. 71.

Harvey, H. W. 1928 (1). Nitrate in the Sea. II. J. Marine Biol. Assoc., N.S., Vol. 15, p. 183.

Harvey, H. W. 1928 (2). Concerning methods for Estimating Phosphates and Nitrates in Solution in Sea-water. Conseil International p. l'Exploration de la Mer. Rapports et Procès-verbaux, Vol. 53, p. 96.

Harvey, H. W. 1931. On the Rate of Photosynthesis by Diatoms. Conseil Int. p. l'Expl. de la Mer. Rapp. et Procès-verbaux, Vol. 75, p. 70 .

IBAÑEz, O. G. 1929. Determinacion del Nitrogeno en sus Formas Amoniacal, Nitroso y Nitrico, en el Agua de Mar. Instituto Español de Oceanografía, Serie II, No. 36.

Marshall, S. M., and OrR, A. P. 1927. The Relation of the Plankton to some Chemical and Physical Factors in the Clyde Sea Area. J. Marine Biol. Assoc., Vol. 14, pp. 837-868.

Orr, A. P. 1926. The Nitrite Content of Sea-Water. J. Marine Biol. Assoc., Vol. 14, 55-61.

Peters, N. 1932. Die Bevölkerung des Südatlantischen Ozeans mit Ceratien. Wiss. Ergeb. Meteor, 1925-27. Band 12. Biologische Sonderuntersuchungen, 1ste Lief., p. 63.

Schreiber, E. 1927. Die Reinkultur von Marinem Phytoplankton und deren Bedeutung für die Erforschung der Produktionsfähigkeit des Meerwassers. Wissenschaftl. Meeresuntersuchungen, Helgoland, Neue Folge. Vol. 16, No. 10, p. 34.

Soot-Ryen, T. 1932. Changes in the Nitrite Content through the Year in North-Norwegian Fjords. Journ. du Conseil, Vol. 7, pp. 246-50.

Stanbury, F. A. 1931. The Effect of Light of Different Intensities, Reduced Selectively and Non-selectively, upon the Rate of Growth of Nitzschia closterium. J. Mar. Biol. Assoc., N.S., Vol. 17, pp. 633-653.

Thayer, I. A. 1930. Colorimetric Determination of Silica in the Presence of Phosphates and Iron. Ind. Eng. Chem., Analytical Edn., Vol. 2, p. 276.

Verjbinskaya, N. 1932. Observations on the Nitrite Changes in the Barents Sea. Journ. du Conseil, Vol. 7, pp. 47-52. 
Wattenberg, H. 1928. A Simple Method for the Direct Estimation of Ammonia in Sea-Water by the Use of Nessler's Reagent. Conseil Int. p. l'Exploration de la Mer. Rapports et Procès-verbaux, Vol. 53, pp. 108-114.

Wattenberg, H. 1931. Die Bestimmung von Phosphat, Nitrat, Nitrit, Ammoniak und Silikat im Meerwasser. Ann. d. Hydrographie usw., Vol. 59, pp. 95-106.

WU, H. 1920. Contribution to the Chemistry of Phosphomolybdic Acids, Phosphotungstic Acids and Allied Substances. Journ. Biol. Chem., Vol. 43, p. 189. 